\title{
The size and burden of mental disorders and other disorders of the brain in Europe 2010
}

\author{
H.U. Wittchen ${ }^{\text {a, }}{ }^{*}, 1$, F. Jacobi ${ }^{\text {a, } 1,2}$, J. Rehm ${ }^{\text {a, b }}$, A. Gustavsson ${ }^{\text {c }}$, M. Svensson ${ }^{\text {d }}$, B. Jönsson ${ }^{\text {e }}$, \\ J. Olesen $^{\mathrm{f}}$, C. Allgulander ${ }^{\mathrm{g}}$, J. Alonso ${ }^{\mathrm{h}}$, C. Faravelli ${ }^{\mathrm{i}}$, L. Fratiglioni ${ }^{\mathrm{j}}$, P. Jennum ${ }^{\mathrm{k}}$, R. Lieb ${ }^{1}$, \\ A. Maercker ${ }^{\mathrm{m}}$, J. van Os ${ }^{\mathrm{n}}$, M. Preisig ${ }^{\mathrm{o}}$, L. Salvador-Carulla ${ }^{\mathrm{p}}$, R. Simon ${ }^{\mathrm{q}}$, H.-C. Steinhausen \\ $1, \mathrm{r}, \mathrm{s}$
}

\begin{abstract}
a Institute of Clinical Psychology and Psychotherapy, Center of Epidemiology and Longitudinal Studies (CELOS), Technische Universität Dresden, Dresden, Germany

b Centre for Addiction and Mental Health, Toronto, Canada

c i3 Innovus, Stockholm, Sweden

d Department of Economics and Statistics, Karlstad University, Sweden

e Department of Economics, Stockholm School of Economics, Sweden

f Department of Neurology, Glostrup Hospital, University of Copenhagen, Copenhagen, Denmark

g Department of Clinical Neuroscience, Karolinska Institutet, Stockholm, Sweden

h Health Services Research Unit, IMIM (Hospital del Mar Research Institute), Barcelona, Spain

i Department of Neurology and Psychiatry, University of Florence, Florence, Italy

j Department of Neurobiology, Care Sciences and Society, Karolinska Institutet, Stockholm, Sweden

k Glostrup Hospital, University of Copenhagen, Copenhagen, Denmark

1 Clinical Psychology and Epidemiology, Department of Psychology, University of Basel, Basel, Switzerland m Department of Psychology, Psychopathology and Clinical Intervention, University of Zürich, Zurich, Switzerland

n Department of Psychiatry and Neuropsychology, Maastricht University, Maastricht, The Netherlands o Department of Psychiatry, University Hospital Center and University of Lausanne, Lausanne, Switzerland p UNIVIDD (Intellectual Disability-Developmental Disorders Research Unit), Villablanca Foundation, Reus, Spain

q European Monitoring Centre for Drugs and Drug Addiction (EMCDDA), Lisbon, Portugal

r Child and Adolescent Psychiatry, Aalborg Psychiatric Hospital, Aarhus University Hospital, Aarhus, Denmark

s Department of Child and Adolescent Psychiatry, University of Zurich, Zürich, Switzerland
\end{abstract}

\begin{abstract}
Aims: To provide 12-month prevalence and disability burden estimates of a broad range of mental and neurological disorders in the European Union (EU) and to compare these findings to previous estimates. Referring to our previous 2005 review, improved up-to-date data for the enlarged EU on a broader range of disorders than previously covered are needed for basic, clinical and public health research and policy decisions and to inform about the estimated number of persons affected in the EU. Method: Stepwise multi-method approach, consisting of systematic literature reviews, reanalyses of existing data sets, national surveys and expert consultations. Studies and data from all member states of the European Union (EU-27) plus Switzerland, Iceland and Norway were included. Supplementary information about neurological disorders is provided, although methodological constraints prohibited the derivation of overall prevalence estimates for mental and neurological disorders. Disease burden was measured by disability adjusted life years (DALY). Results: Prevalence: It is estimated that each year $38.2 \%$ of the EU population suffers from a mental disorder. Adjusted for age and comorbidity, this corresponds to 164.8 million persons affected. Compared to $2005(27.4 \%)$ this higher estimate is entirely due to the inclusion of 14 new disorders also
\end{abstract}

\footnotetext{
${ }^{1}$ Equally shared first authorship.

${ }^{2}$ Also affiliated with Psychologische Hochschule Berlin, Germany.
} 
covering childhood/adolescence as well as the elderly. The estimated higher number of persons affected (2011: $165 \mathrm{~m}$ vs. 2005: $82 \mathrm{~m}$ ) is due to coverage of childhood and old age populations, new disorders and of new EU membership states. The most frequent disorders are anxiety disorders $(14.0 \%)$, insomnia $(7.0 \%)$, major depression $(6.9 \%)$, somatoform $(6.3 \%)$, alcohol and drug dependence (N4\%), ADHD (5\%) in the young, and dementia (1$30 \%$, depending on age). Except for substance use disorders and mental retardation, there were no substantial cultural or country variations. Although many sources, including national health insurance programs, reveal increases in sick leave, early retirement and treatment rates due to mental disorders, rates in the community have not increased with a few exceptions (i.e. dementia). There were also no consistent indications of improvements with regard to low treatment rates, delayed treatment provision and grossly inadequate treatment. Disability: Disorders of the brain and mental disorders in particular, contribute $26.6 \%$ of the total all cause burden, thus a greater proportion as compared to other regions of the world. The rank order of the most disabling diseases differs markedly by gender and age group; overall, the four most disabling single conditions were: depression, dementias, alcohol use disorders and stroke. Conclusion: In every year over a third of the total EU population suffers from mental disorders. The true size of "disorders of the brain" including neurological disorders is even considerably larger. Disorders of the brain are the largest contributor to the all cause morbidity burden as measured by DALY in the EU. No indications for increasing overall rates of mental disorders were found nor of improved care and treatment since 2005; less than one third of all cases receive any treatment, suggesting a considerable level of unmet needs. We conclude that the true size and burden of disorders of the brain in the EU was significantly underestimated in the past. Concerted priority action is needed at all levels, including substantially increased funding for basic, clinical and public health research in order to identify better strategies for improved prevention and treatment for disorders of the brain as the core health challenge of the 21 st century.

Keywords: Prevalence; Disability; Mental disorders; Neurological disorders; Disorders of the brain; Europe

\section{Introduction}

\subsection{Background}

Depression, schizophrenia, panic disorder, drug dependence and insomnia are examples of "mental disorders", while dementia, epilepsy and multiple sclerosis exemplify neurological disorders. Both groups together are also frequently referred to as neuropsychiatric disorders, as "Mental, Neurological and Substance use (MNS, Collins et al., 2011) disorders or more recently and more comprehensively as "disorders of the brain". Until recently, the complexity of disorders with hundreds of specific diagnoses, codified in diagnostic classifications systems (International Classification of Diseases, ICD-10, WHO, 1993; Diagnostic and Statistal Manual of Mental Disorders, DSM-IV, American Psychiatric Association, 1994), was associated with disciplinary fragmentation in research and practice using different concepts and approaches which has significantly impeded a broader and comprehensive appreciation of the size and burden of disorders of the brain. Further, the marginalization and stigma attached to some disorders of the brain have been identified as barriers to a wider recognition of the core relevance of mental disorders (Saxena et al., 2007; Klin and Lemish, 2008; Corrigan, 2004). Both lay persons and professionals are typically unaware of the commonalities and the shared mechanisms of "brain disorders". Further, there is little 
awareness of the full range of disorders of the brain and little knowledge about the size and burden associated with these diseases in the community and the society. The low levels of awareness and knowledge are major obstacles for improved research on the causes and the treatment of disorders, improved allocation of mental health treatment resources and improved provision of care.

During the past decade increasingly stronger evidence has become available documenting that disorders of the brain are not only much more frequent than previously thought but also contribute to a greater burden of disease than previously thought, and should, therefore, be considered as a top global health challenge of the 21st century (Collins et al., 2011; Murray and Lopez, 1996; Prince et al., 2007,WHO, 2001,WHO, 2008; Wittchen and Jacobi, 2005). Numerous epidemiological studies on mental disorders throughout the world have convergently shown with some variability by diagnoses that in each year about one third of the adult population suffers from a mental disorder (Kessler and Üstün, 2008). The Global Burden of Disease studies, that cover comprehensively all disease groups and injury categories (Murray and Lopez, 1996; WHO, 2002; WHO, 2008), have found that increasingly higher proportions of the global burden of disease can be attributed to disorders of the brain. For example, a recent analysis (Collins et al., 2011) estimated that about $13 \%$ of global disease is due to disorders of the brain, surpassing both cardiovascular diseases and cancer. However, such global estimates are of limited value for use in the European Union (EU). These estimates are heavily influenced by the most populous countries and regions of the world, with very diverse population, health, and mortality characteristics, as well as different socio-economic and health care systems.

\subsection{Size, burden and cost of disorders of the brain in Europe}

The lack of EU-specific, comprehensive data on the size, burden and cost of mental and neurological disorders prompted the launch in 2003 of a major European wide interdisciplinary effort coordinated by the European Brain Council (EBC) and the European College of Neuropsychopharmacology (ECNP), involving multiple task forces and panels, and using sophisticated methodological approaches including reanalyses of data sets from epidemiological studies in the $\mathrm{EU}^{3}$ up to the year 2004, which resulted in a series of publications (Andlin-Sobocki et al., 2005; Wittchen et al., 2005). These publications documented the size and burden of neurological (Olesen and Leonardi, 2003; Berr et al., 2005; Campenhausen et al., 2005) and mental disorders (Wittchen and Jacobi, 2005) and provided comprehensive health, economic, and cost data for both groups of disorders. For mental disorders alone it was estimated conservatively that every year $27 \%$ of the total adult (18-65) EU population is affected by a mental disorder. This amounted to over 82.7 million affected persons of the applicable reference EU population 2004 aged 18-65 of 301.7 million people in the 2005 study. Most frequent disorders were anxiety, depressive, somatoform and substance use disorders.

Further, the 2005 report highlighted the tremendous size and range of associated psychosocial impairments and disabilities due to mental disorders and the generally low treatment rates; only $26 \%$ of all cases with mental disorders had any consultation with professional health care services. Among treated cases with mental disorders there was a long delay between onset and first treatment contact and only a small number of patients received minimally adequate interventions (see Kessler and Üstün, 2008, for an overview for the countries participating in

\footnotetext{
3 In addition to the EU-25 (2005 report) and the EU-27 (the present 2011 report), Iceland, Norway and Switzerland were included; the 2011 project covers 30 countries (514 million inhabitants: the 2005 report: 301.7 million, age 18-65).
} 
the World Mental Health initiative). A substantial degree of the unmet treatment and intervention and poor service provision for mental disorders was due to the combined effects of underutilization, underrecognition, under-treatment and lack of resources.

Similarly detailed analyses for neurological disorders were not possible due to differing methods and standards of epidemiological studies which prohibit the derivation of overall prevalence estimates for having any mental or neurological disorder. Nevertheless, mental and neurological data were used to calculate and estimate the patterns and costs of treatment and the health economic implications in terms of total direct and indirect costs for EU nations (Andlin-Sobocki et al., 2005; Wittchen et al., 2005). This modeling revealed that mental disorders are extremely costly. Compared to many somatic diseases, the categories of costs were different with disproportionally high indirect costs and relatively low direct costs of health care. Together with additional epidemiological evidence for selected neurological conditions, the total EU cost burden of disorders of the brain in 2005 was estimated to be close to 386 billion Euros, of which 277 billion Euros were attributed to mental disorders alone.

\subsection{Reasons for a 2011 update}

The 2005 size, burden, and cost study suffered from several limitations particularly with regard to incomplete age ranges (18-65 for most diagnoses) and the diagnostic scope. As a result, mental disorders in childhood and adolescence, as well as frequent disorders of old age and neurological conditions were not included. Further, we were unable to provide consolidated DALY data for all EU member states, because available data were based on specific groupings of countries used by the World Health Organization that could not be applied to the EU. Along with the wish to describe changes that might have occurred since 2005, the limitations of the 2005 study prompted our efforts to improve the epidemiological estimations by incorporating new available study data. We were particularly interested in broadening the previously restricted scope of mental disorders and the age range covered, including as much as possible additional relevant mental and neurological conditions across the lifespan, and improving previously crude prevalence estimates for some disorders.

\section{Goals}

As part of the EBC's and the ECNP's initiative to conduct an updated and improved "Size, Burden and Cost of Disorders of the Brain in Europe" study, we launched a program in 2009 consisting of numerous work groups, organizations, and individuals with interrelated work packages. The major goals of this program were:

1. To provide consolidated best estimates for the 12 month prevalence of mental and neurological disorders for the EU-27 total population in the year 2010 .

2. To cover as far as possible all major disorders for children and adolescents (2-17), adults (18-65), and the elderly (65+ years).

3. To estimate for the total EU-population the number of persons affected by each diagnosis.

4. To estimate the associated DALY burden for mental and neurological disorders for the total EU population, arranged by individual diagnoses and groups of disorders. 
5. To explore indications of increasing or decreasing rates of individual disorders or groups of disorders.

6. To examine the provision of treatment to identify those areas where changes have occurred and those areas with unmet needs for research and/or public health action.

The consolidated size and burden data were further used as input for comprehensive health economic analyses, including cost modeling for all conditions covered. The results of this more extensive cost report are in press ("Cost of Disorders of the Brain in Europe 2011," European Neuropsychophamacology in press).

\section{Methods}

\subsection{Overall strategy}

Similar to our 2005 review, a stepwise multi-method study approach (described in greater detail in Wittchen and Jacobi, 2005) was adopted consisting of a) reiterative literature searches for epidemiological publications and subsequent data analyses of published material on mental disorders, b) reanalyses of existing accessible epidemiological data sets with uniform assessments, and c) supplementary surveys by country to gather input about existing epidemiological databases via national experts.

\subsubsection{Systematic literature search}

The search was conducted by 19 epidemiological panels that were formed for this project, with at least one international expert being responsible for diagnostic groups (see acknowledgements for full information). The epidemiological panels systematically reviewed the existing literature from studies in the general population and in communities with a documented sampling strategy. The respective studies were eligible whenever prevalence estimates for established diagnoses of mental disorders were reported (according to DSM-III, DSM-IIIR or DSM-IV or ICD-10; American Psychiatric Association, 1980, 1987, 1994; World Health Organization, 1993), and established diagnostic instruments with explicit diagnostic criteria of these diagnostic classificatory systems were used. Since such explicit diagnostic criteria were largely unavailable before 1980, our search period was from the early 80 s to 2010 . The epidemiologic chairs were asked to take into account all eligible papers, including those already covered in our report (Wittchen and Jacobi, 2005), to discuss their literature searches with their panel, and to use personal contacts and networks to ensure that no relevant studies were missed. No study was identified that had been overlooked in the 2004 review; this can be regarded as a validation and confirmation of the integrity of the Wittchen and Jacobi (2005) report. Slightly different conventions were adopted for mental disorders covered in the 2005 report and the newly incorporated diagnoses. For example, epidemiological studies of childhood and adolescent disorders, covered in this paper, typically use different assessment procedures which take into account the cognitive and developmental capabilities of children and which also use different conventions than do studies of adults with regard to reporting prevalence findings (dimensional cut-offs, point rather than strict 12month prevalence, etc.). Epidemiological studies on neurological disorders also use approaches and conventions (incidence rather than prevalence studies, inclusion of clinical samples) that differ from those used in mental disorder studies.

The existence of these methodological differences seems to account for the fact that there is not a single study that has examined the full spectrum of disorders simultaneously. Due to the 
substantial degree of comorbidity between disorders, it is not possible to simply aggregate the findings in one single table with one overall count. Thus, it remains impossible to calculate the exact proportion of the total EU population affected by any mental or neurological disorder. Consolidated overall counts are only possible for adult mental disorders because many studies used similar diagnoses, similar instruments, and conventions, allowing for reanalyses of existing data sets and aggregation.

For this reason, we have presented our findings separately for mental disorders in adults (Table 2), and for childhood conditions, personality disorders and selected neurological conditions (Table 3). This manner of presentation allows the direct comparison of our new findings with those from the 2005 report; however, we are unable to take into account comorbidity patterns between mental and neurological disorders or to report estimated overall prevalence of all neuropsychiatric disorders.

\subsubsection{Reanalyses}

Since some publications and reports did not contain prevalence data in the manner needed for the survey, we accessed the original data of some of the countries participating in the ESEMeD project (ESEMeD/MHEDEA 2000 Investigators, 2002) and the Mental Health Supplement of the German National Health Interview and Examination Survey (GHS-MHS; Jacobi et al., 2002, 2004a). These studies provide nationwide general population estimates in community samples for a wide range of disorders using almost identical methods (either MCIDI or WMH-CIDI as a diagnostic instrument). They further allow for aggregated estimates (e.g. "any anxiety disorder"), determination of ratios (e.g. gender, time frames other than 12month) as well as analyses of other indicators, such as impairment and disability or treatment rates (Kessler and Üstün, 2008). This database was supplemented by the longitudinal Early Developmental Stages of Psychopathology study in 14-24 years old (EDSP; Wittchen et al., 1998; Lieb et al., 2000b) to provide estimates for younger people. Reanalyses were conducted by the coordinating center with a restricted set of mental health disorders reported in Table 1, to estimate comorbidity rates, treatment rates, age and gender effects by diagnoses, and to provide an overall estimate of having any disorder (for details, see Wittchen and Jacobi, 2005).

\subsubsection{National experts survey}

This survey was meant to serve as an independent validation component of our data. The role of these country-specific experts was also to provide advice and guidance and to assist in identifying additional studies in regions or whole countries not yet included (e.g. reports not published in an accessible journal). Because epidemiological studies containing prevalence data are not available for many EU countries, we assembled a data bank of national experts to critically review the diagnostic findings. We submitted our data tables to all country-specific experts, independently of whether any data or findings were reported for that country. Experts from all countries were requested to review tables with their "best estimates" (with a confidence interval of $+/-25 \%$ ) for each diagnosis. They were asked to answer the following questions: "According to your expert knowledge or available study findings in your country, are the prevalence estimates in the table a) 'in the range of the respective interval', or b) 'higher', or c) 'lower'?" Experts were encouraged to use the "don't know" category if they were not aware of information for their country concerning the prevalence of a particular diagnosis. Contact was maintained via e-mail or by telephone for questions and discussion. 
Expert inquiries were completed for 27 countries; thus, we received feedback for almost every included country. Despite considerable attempts, we failed to reach experts from Luxemburg, Malta, and Poland. The findings of this survey revealed that our best estimates are by and large acceptable. Notable diagnostic exceptions were:

a) For alcohol dependence, $35 \%$ of all eligible national experts indicated that for their country higher rates should have been estimated. Most of these judgments came from Central and Eastern European countries, what accords with the epidemiological evidence (Rehm et al., 2005a).

b) For three diagnoses a substantial number of countries indicated that a lower 12-month estimate would be more appropriate. Seven experts (from: BU, DK, ES, FI, GR, LV, NE) suggested lower estimates for major depression in their country, 10 experts (from: BU, CY, ES, FI, GR, IT, LV, NE, PT, RO) suggested lower estimates for agoraphobia and nine experts (BU, CH, CY, DK, ES, FI, HU, LV, RO) lower estimates for post-traumatic stress disorder (PTSD).

Different understandings of the diagnosis (e.g. for agoraphobia), or the availability of local study data with lower prevalence estimates, played a key role in the suggested lower estimates (e.g. inclusion of older age without adjustment, different use of diagnostic algorithms in some countries participating in the World Mental Health Surveys) rather than did the existence of national or regional variability.

For several disorders many national experts did not feel confident to make a substantive appraisal, either because the diagnosis was outside their expertise, or because of a lack of relevant data. The most frequently unrated diagnoses because of a lack of evidence were narcolepsy $(81 \%)$, sleep apnoea $(77 \%)$, insomnia (54\%), borderline personality disorder $(50 \%)$, conduct disorder (46\%), and dementia and somatoform disorders (42\%). A table with the distribution of the ratings by disorders is provided in the online appendix to this article. Online materials can be accessed at: www. psychologie.tudresden.de/i2/klinische/sizeandburden.html.

\subsection{Diagnostic spectrum}

Table 1 lists all included diagnostic categories, together with their respective ICD-10-codes, the number and citation of selected epidemiological studies we reviewed to arrive at our best estimates for 12-month prevalence, and the respective age range to which these estimates apply. Because of space restrictions, those studies reviewed for our 2005 report are not repeated in this table, but are highlighted in the reference section. The diagnostic categories used throughout this paper are not entirely consistent with ICD-10 labels. This is due to the fact that most research is conducted using the DSM system which uses terminology not entirely consistent with the ICD-10.

\subsubsection{Diagnoses of mental disorders covered in the 2005 report}

Only three changes were made regarding the diagnostic spectrum covered in our 2005 report: (i) PTSD was added to the anxiety group because several new studies allowed us to address this disorder with sufficient quality. (ii) "Illicit substance use disorders" (which was one category in 2004; Rehm et al., 2005b) was separated into two groups of major interest, namely opioid and cannabis dependence. (iii) Eating disorders (which were one category) are now separately reported (anorexia nervosa and bulimia nervosa). For these diagnoses, the 
availability of original data from several studies allowed us to calculate the median and the interquartile range (IQR), along with a calculated gender ratio. Further, for these diagnoses, comorbidity rates and prevalence rates for having any of these diagnoses could be estimated.

\subsubsection{Additional diagnoses for 2011 - report}

Evidence for all additional and new diagnoses covered was based entirely on reviews and expert rated "best-estimates". Because no access was possible to the original data, and since most studies were restricted to one diagnosis only no comorbidity analyses were feasible, and no overall prevalence estimates for having any mental disorder taking into account the full range of diagnoses could be calculated.

Childhood and adolescence disorders. A total of 37 eligible studies were included, describing a broader group of disorders that typically have their onset in childhood and which might extend into adulthood or over the whole lifespan. Examples of disorders which fall into the latter category include autism and mental retardation. Additional specific disorders are: (i) pervasive developmental disorders/autism spectrum disorders, (ii) hyperkinetic disorders/attention deficit hyperactivity disorders (adhd), (iii) conduct disorders (including oppositional defiant disorders, and (iv) mental retardation, also called "intellectual disability disorder" (IDD), which denotes a broader syndrome group irrespective of its etiology (similar to dementia) characterized by a deficit in cognitive functioning before the acquisition of skills through learning (Salvador-Carulla and Bertelli, 2008).

Personality disorders. Only two of nine subtypes, namely borderline/ emotionally unstable personality disorder and dissocial/antisocial personality disorder, are reported here (due to reasons related to the available cost studies in the overall project), but in the two sources identified for those disorders the same prevalence information is also given for the other F60 diagnoses.

Sleep disorders. Sufficient data evidence were available to include sleep disorders, namely (non-organic) insomnia (8 studies), hypersomnia (2 studies), narcolepsy (3 studies), and sleep apnoea (14 studies).

Dementia. We reviewed evidence from a total of 17 studies, extending a review paper by Berr et al. (2005), and covering all types of dementia irrespective of their etiology, without considering diagnostic subtypes. We decided to use as the applicable age range 60 and above (we used $65+$ in the 2005 report) to include early onset disorders.

\subsubsection{Neurological disorders and conditions and other disorders of the brain}

Although we reviewed the literature for several other disorders (brain tumor, epilepsy, headache, multiple sclerosis, Parkinson's disease, stroke and brain trauma), and identified a high number of excellent studies (see "Cost of Disorders of the Brain in Europe 2011", European Neuropsychophamacology in press), the type and form of these estimates in the literature could not be integrated into the approach chosen for this paper. Unlike the disorders discussed above, studies concerning neurological disorders and conditions and other disorders of the brain largely refer to clinical and treatment samples and provide no comparable 12month estimates. As a result, we could not include these data in the present analysis. However, we will report some crude figures in the discussion to enhance the utility of our overall estimates. Further, some of the disorders mentioned are presented in the chapter on DALYs. 


\subsection{Literature search and criteria for inclusion}

In an initial step, a series of database searches (Web of Knowledge, PubMed, PsycINFO, SCOPUS) were performed by the epidemiological panels to identify all epidemiological studies on the included diagnoses conducted in European regions. The search (time period "old" disorders: 2004-2010; "new" disorders: 1990-2010) used the following key words and related terms: epidemiology, prevalence, incidence, community, general population, mental disorders, psychiatric diagnoses/diseases, names of the 30 included European countries, and the specific diagnostic terms (e.g. for psychotic disorders: psychotic, psychosis, schizophrenia, delusional, schizoaffective etc.). Each of these hits was cross-checked and evaluated, resulting in 840 references after elimination of duplicates and the first screening of titles and abstracts. Among the resulting 840 references the overwhelming majority were excluded for the following reasons: a) no relevant prevalence data was reported in the publication, b) no data was from a European country, c) the samples were clinically or otherwise based. (Detailed literature search descriptions for selected diagnoses are available in the online appendix to this article.) To be included in the systematic review and the subsequent analyses, the following criteria needed to be met:

- Conducted in an EU-27 country, plus Iceland, Norway and Switzerland (the total number of European countries included was 30);

- Use of a population-based approach (i.e. subjects sampled from a defined community or the whole country, no clinical studies);

- Use of explicit diagnostic information according to established diagnostic criteria, by use of an established diagnostic instrument, either according to ICD-10 (WHO, 1993) or DSM-IIIR/DSMIV (APA, 1994). Diagnostic information should be assessed by one of the following diagnostic instruments: DIS (Robins et al., 1981), CIDI (Robins et al., 1988) and variants thereof, SCAN (Wing et al., 1990) or related approaches, e.g. SCID-II (First et al., 1997) for personality disorders, or the Diagnostic System for Mental Disorders in Childhood and Adolescence (DISYPS; Döpfner et al., 2008a). Studies assessing psychopathology and mental health exclusively by means of questionnaires or screening instruments (e.g. GHQ, Goldberg and Hiller, 1979; CIDI-SF, Kessler et al., 1998; MHI-5, Berwick et al., 1991; PHQ-9, Kroenke et al., 2001) were not included. Diagnostic prevalence findings should refer to the past 12 months, although shorter intervals were also considered.

- Age groups covered: The decision to include a broader age spectrum than was previously considered was made despite the fact that studies in children, young adolescents, and the elderly use different assessment instruments and might have specific restrictions with regard to reliability and validity, meaning there should be caution in merging and aggregating the data. Therefore, we restricted, in some instances, the applicable age range, with contingent changes regarding the estimation of the number of people affected (see Table 1).

\subsubsection{Other data sources}

Aside from community studies, we also identified studies that provide information about prevalence in primary care settings, as well as recognition and treatment rates. These studies typically investigate the prevalence of one or two target diagnoses in unselected primary care populations and refer to cross-sectional 2 week or 1 month diagnoses, rarely using established diagnostic instruments. Although primary care studies can provide important additional 
information, we decided to give priority to the population- based approach and do not report findings of primary care studies here. We also received some data from nationwide and regional registers of services (e.g. from Denmark and Belgium). However, because of the extremely high variability in diagnostic standards and reporting conventions of the register information, we felt unable to aggregate such data in a meaningful statistical way. Service register data - although highly valuable in local health care research and planning (e.g. reports from the Health Research Board in Ireland) - are problematic for our purposes because they rely only on identified patients, and it has been known that people with mental or psychiatric disorders often do not seek treatment or do not present with mental health problems as a reason for consultation and are therefore not identified as cases (Goldberg and Huxley, 1980). This was also the basis for our being unable to include some interesting mental health studies and databases that were identified during the country specific expert surveys (e.g. from Hungary, Latvia, Lithuania, Portugal, Romania). Studies not yet published (i.e. identified during panel discussions or the expert survey) were not considered.

\subsection{Determination of "best estimates" and derivation of overall estimates}

12 month prevalence estimates will be reported in this paper as the most frequently used time frame across studies. For a few studies only point prevalence rates were available; in these cases the point prevalence rates were projected to a 12 month estimate using extrapolations from studies where both point and 12 month prevalence rates were available.

Aggregation of diagnostic findings for each diagnosis across all EU member states was done most often by reporting median percentage and IQR (where at least five studies were available). For several diagnoses, the epidemiological panels derived "best estimates" by judgment taking into account the median and range. This was the case whenever the median appeared to be heavily biased by some specific methodological factors. In this instance, panel experts could choose to determine the "best estimate" from a reference study (e.g. when after evaluation by the epidemiological panels the median was considered to be biased by some studies with outlier prevalence, most frequently due to selective attrition due to using 2-stage designs, limitations to a certain age group while evidence suggests substantially different prevalence by age, power, etc.). Although weighting schemes were also examined and applied for some diagnoses, the unweighted findings are reported in this paper, unless otherwise indicated.

For some disorders, we took into account disorder-specific variations between countries. For example, for alcohol dependence documented evidence of substantial changes (WHO-EURO, 2010) as well as mental retardation (Durkin, 2002; Maulick et al., 2011) mandated extrapolations in order to derive appropriate estimates for the number of people affected (three European regions of different substance use disorder levels). For other disorders, agegroup specific differences were considered, such as for Generalized Anxiety Disorder (GAD), for which higher rates in the elderly have been found (Goncalves et al., 2011).

In summarizing prevalence data, we present a consolidated overall prevalence for having any mental disorder. This overall estimate is based on 13 diagnoses of mental disorders for which we had access to the original data in order to determine the number of subjects having any of these 13 diagnoses, thus avoiding double counting by accounting for comorbidity. These 13 diagnoses are almost identical to those used in the 2005 report. For the new diagnoses, an empirical approach was not possible because the prevalence data for these 14 diagnoses were not available and there were no studies covering these disorders jointly within one study design. To arrive at an aggregated prevalence, two adjustments were necessary: 
1. Adjusting age-group-specific prevalence: For disorders with a small applicable age range (i.e. for child/adolescent disorders or for dementia), we calibrated the age specific diagnostic prevalence to reflect the total population of all ages. Thus, the resulting adjusted prevalence score for such diagnoses is necessarily only a fraction of the prevalence estimate reported in the respective studies. The adjusted score refers to the total reference population, consistent with the conventions used for the 13 mental disorders mentioned above.

2. Adjusting for comorbidity: In order to avoid double counting we made several assumptions based on theoretical and restricted empirical grounds. For personality disorders, we assumed that these cases would most likely already be counted as having at least one other mental disorder. Therefore, we excluded this group of disorders from the overall prevalence estimation. For insomnia, we assumed high comorbidity with depression and some anxiety disorders, and discounted the adjusted rate by $50 \%$ as a consequence. For all other disorders, we assumed they would not have been counted elsewhere. This applies, for example, for dementia and mental retardation, both of which are typically excluded from community surveys with standardized interviews.

We are aware that one "representative" prevalence estimate might be problematic in terms of "over-equalization" of subpopulations (even within one country with perhaps very diverse and different communities in certain urban and rural areas). But, in light of the fact that no substantial between-country variation can be expected in most diagnoses (with substance use disorders as the most relevant exception), the choice of this "best estimate" approach was the most straightforward approach within our ECNP/ EBC program to combine epidemiological and cost data on a public health level in the EU with its over 500 million inhabitants.

\subsection{Disability adjusted life years lost (DALY)}

The DALY is a measure of overall disease burden, expressed as the number of years lost due to ill-health, disability, or early death. The DALY extends the concept of potential years of life lost due to premature death and includes equivalent years of 'healthy' life lost by virtue of being in a state of poor health or disability, thereby combining mortality and morbidity into a single metric (WHO, 2008). DALYs are calculated based on incidence and duration for the respective disorder group.

DALYs from the latest available Global Burden of Disease update (for 2004, conducted and published by the World Health Organization in 2008) were obtained by the World Health Organization by country, GBD disease category, sex, and age. Based on these data, disease and gender-specific standardized and unstandardized rates of DALYs per 10,000 were calculated for the EU using the 2008 population of all 27 member states as a reference (Rothman et al., 2008). In addition, these standardized rates were also calculated for three regions within the EU: Western Europe, comprising Austria, Belgium, Cyprus, Denmark, Finland, France, Germany, Greece, Iceland, Ireland, Italy, Luxembourg, Malta, Netherlands, Norway, Portugal, Spain, Sweden, Switzerland, United Kingdom; Central Europe: Bulgaria, Czech Republic, Hungary, Poland, Romania, Slovakia, Slovenia; and Eastern Europe: Estonia, Latvia, Lithuania.

Unfortunately these data do not cover the full spectrum of all disorders discussed in this paper. Particular significant deficits were the lack of data regarding social and specific phobias, GAD and somatoform disorders, all of which are highly prevalent and quite impairing. Further, the diagnostic definitions for all diagnoses are not entirely consistent with 
the present study. For example, DALYs are usually reported for alcohol use disorders, whereas in our study only DALYs due to alcohol dependence are reported. Further, DALYs due to drug use disorders are usually considered, whereas we are limited to dependence on cannabinoids and opioids.

\section{Results}

\subsection{2 month prevalence of mental disorders (update of the 2005 report)}

Table 2 presents information about the number of studies covered, the prevalence range of studies and median (Md) across studies, with the IQR and gender ratio (females:males) as derived from the findings of community studies. The resulting consolidated "expert-based best estimate" of the 12 month prevalence is highlighted, along with the estimated number of subjects in the EU affected within the applicable age ranges.

The updated and improved 2011 estimates for disorders listed in Table 2, based on a substantially higher number of studies as compared to the 2005 report, are almost identical to our previous estimations. No substantial changes were observed in the more recent studies when accounting for methodological differences, indicating that no substantial increases or decreases were identified. Except for substance use disorders with a marked preponderance of males, and psychotic disorders with a slight preponderance of males, females are affected approximately 2-3 times more frequently than males by the other mental disorders listed in Table 2.

With respect to the "best estimate" data in the table, the most prevalent 12 month disorders are anxiety disorders (total 14\%), specific phobias (6.4\%), social phobias (2.3\%) agoraphobia $(2 \%)$ and panic disorder $(1.8 \%)$. Although these numbers are almost identical to our previous report, new data on GAD and PTSD suggest remarkable differences by age group. For GAD, evidence suggests highest rates (3.4\%) among the elderly (65+), and considerably lower rates $(1.7 \%)$ in the $14-65$ age group, while PTSD rates decline by age (14-34: 2.9\%, 35-65: 1.3\%, $65+: 1.1 \%)$. Thus, we used these different rates to calculate the total number of persons affected. It should also be noted that for some anxiety disorders "best estimates" tend to be slightly higher than the observed median due to the fact that more recent studies did not cover younger age groups. We therefore accounted for this "methods effect" by imputing the higher rates to reflect the true rates in the applicable age range $(14+)$.

Consistent with the 2005 report, mood disorders are the second most frequent group of disorders $(7.8 \%)$, dominated by major depression (6.9\%). The lower observed median was assumed to be due to the inclusion of more recent studies that have included the elderly (65+ years of age) for which remarkably low prevalence was found, inconsistent with clinical studies. The experts considered the diminished elderly rates to be a well documented (Knauper and Wittchen, 1994) artifact of standardized diagnostic instruments. Thus, the "best estimate" of $6.9 \%$ for adults (14-65) was considered to be more appropriate.

Somatoform disorders that include somatisation disorder, undifferentiated somatoform disorder, pain disorder and hypochondriasis ranked number 3, with an observed median of $6.3 \%$ (identical to the 2005 report estimate). However for the purpose of this study, the estimate $6.3 \%$ was discounted to avoid double counting with the new neurological category of headaches by excluding all somatoform cases where the disorder was exclusively due to headache. This was done by reanalysing the available data sets and recalculating the 12month rates without taking into account headache symptoms, resulting in best-estimate of 
4.9\%. It should be further noted that we did not include three studies with higher estimates, namely (Pakriev et al., 1998, conducted in Russia), Leiknes et al. (2007, no DSM compatible diagnoses) and Stefansson and Lindal (2009, self report data).

Alcohol dependence (3.4\%) and opiod and cannabis dependence rank together as the fourth most frequent group of disorder. Rates for opioid dependence have been shown to decline from a relatively high $0.4 \%$ in late adolescence to a considerably lower estimate of $0.1 \%$ in the elderly. Thus, assuming that the median derived from studies in younger age groups applied to the ages considered in the report, namely 15-64, there would be an overestimation of the number of persons affected. A similar effect is observed for cannabis dependence (age group drop from $1.8 \%$ to $0.3 \%$ ). For these disorders we use different prevalence for different age group subsets of the EU population to calculate the number of persons affected.

Psychotic (1.2\%) and eating disorders rank among the less prevalent 12 month diagnoses. For psychotic disorders, the challenge was that many studies exclusively report rates for schizophrenia as defined by DSM III and DSM-IV; the higher best estimate accounts for this by imputing the ratio of psychotic vs. schizophrenia prevalence. For eating disorders, higher rates were estimated for the age range $14-17(0.5 \%$ and $0.9 \%)$ and lower rates for the age range $18-65(0.2 \%$ and $0.1 \%)$, accounted for in the calculation of the number of persons affected.

\subsection{2 month prevalence of other mental disorders (2011 addition)}

Table 3 summarizes the additional mental disorders by indicating the number of studies included for each diagnosis, the range of findings, the "expert based best estimate" derived and agreed upon by the epidemiological panels, information about the number of people affected, the applicable age ranges, and the gender ratios. The data reported in this table are based exclusively on reviews and expert opinion.

\section{Personality disorders}

The two studies that met inclusion criteria are prominent and include a review of the literature (citing mostly studies from outside Europe). They focus on current symptomatology with good methodological quality. The community studies from the UK (Coid et al., 2006) and Norway (Torgersen et al., 2001) show almost identical prevalence estimates of 0.7 for borderline personality disorder and antisocial personality disorder $(0.6 \%)$. These estimates are lower compared to recently reported U.S. lifetime prevalence of 3.6\%-5.9\% (Grant et al., 2004, 2008; Huang et al., 2009), but in light of their stringent methodology, the estimates from the UK and Norway can be regarded as conservative.

\section{Childhood and adolescent disorders}

A considerable number of studies were available for attention deficit hyperactivity disorder (ADHD)/hyperkinetic disorders (F90.x), conduct disorders (F91.x, CD), and pervasive developmental disorders (PDD), including autism, Asperger's syndrome, PDD-NOS, and the very rare childhood disintegrative disorders (F84.x). The mean 12 month prevalence rates used in this report are based on the mean prevalence rates of all eligible studies using sample size as a weight in the mean calculation. This led to a prevalence rate of $5 \%$ for ADHD and $3 \%$ for CD for ages 6 to 17 and 5 to 17 respectively. The boy-girl ratio for ADHD and CD is estimated to be 3:1. Further, it was estimated that the prevalence rate decreases in adolescence for ADHD, whereas increasing rates for conduct disorders were observed in adolescence. 
For pervasive developmental disorders (PDD), our searches identified a recent review article which analyzed 43 studies on the prevalence of autism spectrum disorders from birth to early adult life with most surveys including a school-aged sample and an overall age of 8.0 years (Fombonne, 2009). The prevalence rate is chosen based on the mean prevalence among studies published since 2000, considering that the review indicated that there has been a statistically significant increase in estimated prevalence rates over time. Based on this argument, a prevalence rate of $0.64 \%$ is used in this report. The boy-girl ratio was, based on the review, assumed to be $4: 1$. These figures are based on the analysis of a total of 19 epidemiological surveys, including 9 from European countries. A recent community study (Brugha et al., 2011) revealed a slightly higher estimate (1\%) in adults; however, because of the low sample size and the large confidence interval, overlapping with our best estimate, we felt that our estimate was better substantiated.

\section{Mental retardation}

Intellectual developmental disorder (IDD) refers to what has previously been denoted as mental retardation (ICD-10: F70-F79) or intellectual disability (Schalock et al., 2007), and we use this new terminology in order to comply with the forthcoming proposals for ICD-11 (Salvador-Carulla et al., in press) and DSM-5 (www.dsm5.org). The derivation of the overall estimate was based on a total of 52 studies from the only international systematic review on IDD published to date (Maulick et al., 2011), with an expert-base adjustment for the European case. This meta-analysis assessed studies published between 1980 and 2009, and provided an overall estimate of the prevalence of intellectual developmental disorders/intellectual disability of 10.37/1000 population. Meta-analysis was done using random effects to account for heterogeneity, and subgroup analyses by gender and country income level were also performed. This meta-analysis included 17 epidemiological studies from 9 countries from the EUR-A subregion. ${ }^{4}$ Unfortunately, no studies were included from Eastern Europe, where rates of IDD are expected to be higher.

In order to provide a global 12-month prevalence of IDD for Europe, and taking into account the lack of data from Eastern Europe, a conservative expert-based estimate of 10.00/1000 has been chosen for this study. The adjusted estimate was agreed upon by a group of four experts on IDD and was motivated by several factors. Higher prevalence rates have been described in low- and middle-income countries as compared to prevalence rates in high-income countries (Durkin, 2002; Maulick et al., 2011). The global prevalence for middleincome countries in the meta-analysis was $15.94 / 1000(95 \%$ CI $13.56-18.32)$ vs. 9.21 (95\% CI 8.46-9.96) for highincome countries. The mean prevalence in Western Europe was $7.86 / 1000$ population, which is below the general estimate for all high-income countries in the same systematic review. Although some epidemiological studies in Central and Eastern Europe indicate rates between 3 and 5/1000, most reported studies are above 20/1000 (WHO, 2005). Studies indicate a female-male ratio varying between 0.7 and 0.9 among adults and between 0.4 and 1.0 among children and adolescents (Maulick et al., 2011). In this report, we assume a female-male ratio in the midpoint of that interval at 0.8 .

\section{Sleep disorders}

A total of 27 studies were taken into account for sleep disorders, with the most stable estimates for sleep apnoea (best estimate 3.0\%), narcolepsy $(0.02 \%)$ and hypersomnia $(0.8 \%)$. For the best estimate for nonorganic insomnia of $7 \%$, one should acknowledge that an

\footnotetext{
${ }^{4}$ Eur-A: 27 countries with very low child and adult mortality (the countries included in the meta-analysis are italicized): Andorra, Austria, Belgium, Croatia, Cyprus, the Czech Republic, Denmark, Finland, France, Germany, Greece, Iceland, Ireland, Israel, Italy, Luxembourg, Malta, Monaco, the Netherlands, Norway, Portugal, San Marino, Slovenia, Spain, Sweden, Switzerland and the United Kingdom (Northern Ireland).
} 
accurate method to delineate insomnia from other mental disorders in which insomnia is a key symptom currently does not exist. Thus, one might assume a substantial overlap.

\section{Dementia}

For dementias, the overall estimate of $5.4 \%$ for age $60+$ was based on the weighted mean of all studies across 5 age groups, namely 60-64: 0.5\%, 65-69: 0.9\%, 70-74: 2.6\%, 75-79: $6.1 \%, 80-84: 14.8 \%, 85+: 23.7 \%$. The number of persons affected was determined by taking into account age group and country where available, otherwise the European mean was imputed.

\subsection{Prevalence and number of persons affected: comparison of 2004 vs. 2010 estimates}

\section{Prevalence 2005 vs. 2011}

Table 4, Group A compares the 12 month estimates from the 2005 report with the findings for 2011 for those diagnoses where such a comparison is technically feasible. There are no indications of remarkable differences between the 2005 and 2011 findings. All 2011 best estimates are within the $95 \%$ confidence intervals estimated for 2005 , suggesting that none of the disorders listed has either substantially increased or decreased in prevalence. The few minor differences in Table 4 are due to technical changes in disorder definitions, necessitated by the inclusion of additional disorders, namely somatoform (deletion of headache), illicit substance dependence, and eating disorders (a more detailed diagnostic breakdown) and do not reflect true changes. Consequently, there is no difference in the overall 12 month prevalence of having any of these disorders (27.4\% in 2005 vs. $27.1 \%$ in 2011).

Group B of Table 4 lists the additional disorders providing overall prevalence estimates. Since these disorders were not included in the 2005 report, no comparison data can be presented. The best estimates for each disorder are consistent with the results in Table 3; however, there are a few noteworthy differences. Hyperkinetic/ADHD and conduct disorder prevalence estimates for children and adolescents were adjusted to reflect the same EU reference population as the disorders in Group A. As a result of this adjustment, the total prevalence rate drops from 5\% (for subjects aged 6-17) to $0.6 \%$ (taking into account the respective applicable age ranges for each diagnosis). Similarily for the same reasons, the estimated prevalence for conduct disorders drops to $0.4 \%$ and for dementia from 5.4\% (ages $60+$ ) to $1.2 \%$. This adjustment has no effect on the number of persons affected which remains unchanged.

For insomnia, as described above, the original prevalence of $7 \%$ was discounted because of assumed comorbidity with depression and anxiety; the discounted prevalence rate is $3.5 \%$, with an associated drop in the estimated number of persons affected from 29.1 to 14.6 million. To further avoid the risk of double counting, the prevalence rate for personality disorders was not taken into account in the overall prevalence estimate.

Taking all these adjustments together, the additional diagnoses have a total overall prevalence of $11.1 \%$. Taking Group A and Group B disorders together, we assume a total overall prevalence for the 27 diagnoses of $38.2 \%$.

\section{Number of persons affected (Group A)}

The number of people affected by a specific disorder is substantially higher than in 2005 , due to the increase in the EU population since 2005 (adoption of new member states) and the 
broader age ranges chosen (inclusion of children and the elderly, age-group specific estimates) for many diagnoses. This necessarily also implies that a substantially larger proportion of the EU population is included in absolute numbers. Additionally, increases in life expectancy might have played a role for disorders in the elderly. Accordingly, the overall number of persons affected by any (group A) mental disorder reported in the 2005 report (82.7 million) is now substantially higher (118 million, see Table 4). A substantial further change in prevalence and the number of persons affected is attributed to the additional diagnoses not covered in the 2005 report. Even after accounting for the risk of double counting by not including personality disorders or $50 \%$ of the insomnia cases, the total prevalence of $11.1 \%$ for additional Group B diagnoses equals 46.7 milion persons affected. Taking diagnostic Groups A and B together, this amounts to an estimated total number of persons affected by any listed disorder of over 164 million.

\subsection{Disability and burden: DALYs attributable to mental and other disorders of the brain in Europe}

The DALY is a health gap measure for burden of disease, capturing both years of life lost due to premature mortality and years of life lost due to living with disability. Overall, the burden of disease in mental and other disorders of the brain is mainly due to disability, i.e., these disorders impact on the daily functioning of people, rather than leading to premature mortality compared to cancer or cardiovascular disease (WHO, 2008).

In the EU, mental and other disorders of the brain are responsible for a huge proportion of overall burden of disease: almost 1 in 3 of all years of life lost due to premature mortality in women, and almost 1 in 4 in men are due to disorders of the brain (see Table 5 and Fig. 2). These figures are conservatively estimated, as only half of all the DALY caused by stroke were integrated (a usual convention as stroke is also part of cardiovascular disorders).

The three most important contributors to burden of disease are depression (7.2\% of the overall burden of disease in Europe), Alzheimer's disease/dementia (3.7\%) and alcohol use disorders (3.4\%). There are clear gender differences: women were disproportionally affected by depression (one in 10 healthy years of life lost is due to this disorder, or $10.3 \%$ of all the DALYs), while for men alcohol use disorders are the biggest relative contributor to the disease burden in Europe (5.3\% of all the DALYs; see Table 5).

There are also some regional differences. Overall, for men, the highest rates of DALYs can be found in the Eastern part of the EU (Baltic countries), again mainly driven by alcohol use disorders. Rates in the rest of Europe are fairly similar for men, with Eastern Europe being slightly different from the rest with less depression, more epilepsy (again partly caused by alcohol) and lower rates of Alzheimer's and other dementia (due to significantly lower life expectancy — Zatonski et al., 2008). Western Europe has relatively more burden of disease caused by drug use disorders. For women, overall disease burden varies much less between regions and countries (women also have much less variability in life expectancy between European countries or regions than men - Zatonski et al., 2008), but again alcohol use disorders are proportionally higher, and Alzheimer's/dementia proportionally lower than in the rest of Europe.

\section{Discussion}

This report provides for the first time consolidated data on the current size and the burden of mental disorders and neurological disorders for the EU. Based on a complex interdisciplinary 
effort, structured literature reviews, reanalyses of existing data sets, and appraisals, we describe the 12 month prevalence and the associated disability burden. Extending our previous 2005 report, we cover the 27 EU countries plus Switzerland, Norway and Iceland, a much broader range of diagnoses and a broader age range than in our 2005 report. The main findings are:

1. Every year over $38.2 \%$ of the total EU population suffer from at least one of the 27 mental disorders covered. This corresponds to an estimated 164.7 million persons.

2. This new 2011 prevalence estimate of $38.2 \%$ is considerably higher than the previous estimate of $27.4 \%$, provided in our 2005 report. The 2005 report estimate was based on a restricted number of 13 diagnostic groups, restricted to age groups 18-65, and highlighted to be an extremely conservative estimate. The present report adds a total of 14 additional diagnoses, now more appropriately reflecting the true size of mental disorders across all age groups.

3. No indications were found for increasing or decreasing rates of mental disorders from 2005 to 2011 when exactly the same diagnoses are considered (27.4\% in 2005 vs. $27.1 \%$ in 2011$)$. Thus, the apparent increase in prevalence is entirely due to including additional diagnoses.

4. The estimated number of persons affected in the EU is substantially higher ( 82.7 million in the 2005 report vs. 164.7 million in 2011). This is due to the joint effects of a larger EUreference population (now total EU population, broader applicable age ranges for study findings), resulting in a change from 82.7 to 118 million for the 2005 diagnoses, and the coverage of 14 new diagnoses, adding a further 46.7 million cases.

5. The most frequent mental disorders in terms of the estimated number of persons affected across all age groups are: anxiety disorders (69.1 million), unipolar depression (30.3 million), insomnia (29.1 million), somatoform disorders (excluding headache symptoms) (20.4 million), alcohol (14.6 million), opiate (1.0 million) and cannabis dependence (1.4 million), dementias (6.3 million), mental retardation (4.2 million) and childhood/ adolescent disorders, such as attention-deficit-hyperactivity disorders (ADHD) and other hyperkinetic disorders (3.3 million).

6. Since we chose a conservative approach to deriving the prevalence estimates and avoided double-counting by considering comorbidity amongst included disorders, our new 12 month prevalence estimate of $38.2 \%$ for mental disorders with over 164 million persons affected every year appears to be a reasonable and well supported "best estimate".

7. From a more comprehensive perspective of "disorders of the brain" that includes mental and neurological disorders, we must assume that the true size of "disorders of the brain" in the EU is almost certainly considerably larger. As displayed in Fig. 1, neurological disorders affect dozens of millions of persons in the EU. However, we refrain from including these numbers in the current calculations and avoid guessing an overall prevalence and number. This is because there are simply no sufficient data available that would allow such calculations without a substantial risk of inappropriately inflating the prevalence and size estimates. We do not know yet how mental and neurological disorders overlap longitudinally and, thus, would introduce a considerable double counting bias.

8. The disability burden of mental and neurological disorders is immense. Our revised estimates for neuropsychiatric conditions combined account for $30.1 \%$ of the total disease 
burden in females and $23.4 \%$ in males. These new estimates also reveal that for the EU mental disorders account for considerably higher proportions than previously thought. In terms of DALY, depression has already become by far the most burdensome disorder of all diseases in the EU.

9. Unlike previous DALY analyses, our consolidated analyses for the EU-27 countries also reveal substantially different patterns of burden for males and females, and a rank order of the most disabling diseases considerably different from previous publications.

Several limitations need to be acknowledged. (i) To estimate the prevalence for diagnoses we relied on studies that revealed for some diagnoses quite different methodological standards and approaches. (ii) Although we tried to account for such effects, no consistent strategy could be adopted. Because of these problems, our prevalence findings and total EUpopulation estimates should be regarded with caution. (iii) For many countries no epidemiological data were available on the majority of diagnoses. Our assumption that the prevalence estimates from some EU countries can be generalized to other EU countries is questionable and, thus, requires future examination. (iv) The findings rely entirely on 12 month prevalence estimates or post-hoc derivation of such a measure for a restricted range of all existing mental and neurological diagnoses. (v) For methodological reasons studies typically covered only one diagnosis, or a restricted set of diagnoses, or were very limited to certain age groups. Thus, the calculation of overall rates and extrapolation to broader age ranges are based on potentially imperfect assumptions and should be regarded with caution.

(vi) The data base used to estimate DALYs refers to data from theWHO and not the data base used in this paper. The data do not cover the full spectrum of all disorders discussed in this paper. Particular significant deficits were the lack of data regarding social and specific phobias, GAD and somatoform disorders, all of which are highly prevalent and quite impairing. Further, the diagnostic definitions for all diagnoses are not entirely consistent with the present study. For example, DALYs are usually reported for alcohol use disorders, whereas in our study only DALYs due to alcohol dependence are reported. Similarly, available data are limited to lead caused mental retardation and are thus most likely a considerable underestimation of true burden (Stouthard et al., 1997).

\subsection{Mental disorders are the core health challenge of the 21st century}

Taking these limitations into account, our data could still be considered as a major milestone in our understanding of the utmost significance of mental and neurological disorders. The increasingly broad and methodologically improved database that has become available over the past decade has allowed us to not only provide considerably improved estimates based on a wealth of available studies, but also to be much more comprehensive with regard to the diagnostic spectrum and with regard to the age groups covered. In particular, it is noteworthy that all studies are based on rigid criteria that ensure that assigning a diagnosis demands presence of a clinically relevant disorder and not simply a "mental health problem". It has to be acknowledged, though, that in our choice of diagnoses we were confined to those disorders for which sufficient data were available. It is fair to state that they are still significant epidemiologcial research gaps (see below). But at least we were in a better position than 2005 to present a fuller picture of the true size and burden in Europe. In fact, we are unaware of any other study that has ever covered such an extensive range of mental disorders and selected other disorders of the brain.

This unique situation, however, makes it also challenging to make meaningful comparisons with other studies. Our estimate of over $38 \%$ for the 12 -month prevalence of 27 major 
diagnoses of mental health most probably will not be a surprise for psychiatric epidemiologists and researchers involved in longitudinal studies. Moffitt et al. (2010) has recently highlighted the issue of how to determine the "true" prevalence of mental disorders by showing that the prevalence of disorders approximately doubled in prospective as compared to retrospective data. This suggests that past estimates of mental disorders in crosssectional designs might lead to very conservative estimates. The implications of this finding for etiological theory, construct validity of diagnoses, public perception of stigma, estimates of the burden of disease, and public health policy are still unresolved. The core question is how to utilize our findings and best estimates now, whether or not our estimates will be supported and extended by firmer evidence in the future. What do these numbers mean and imply, and how can they be used for improving the future?

From a broader perspective, our prevalence findings underline impressively that mental disorders as well as neurological disorders must be considered to be Europe's foremost health care challenge of the 21 st century.

The challenges are complex. There are dozens of group of disorders and hundreds of specific diagnoses that might require preventive, therapeutic and rehabilitative interventions of different types and intensity in different age groups. The current availability of effective, though frequently not optimal treatments, the current absence of absolute cure, and the dearth of preventive interventions for mental and other disorders of the brain demand concerted action on all levels. This includes innovative basic research into the causes as much as the identification of new targets for psychological treatments and pharmacological drug intervention as well as translational and public health research. Most importantly, it also requires a rethinking of our current standards of provision for mental health care in general. As the disability and societal burden of brain disorders will increase further, simply due to increased life expectancy, there is an immediate need for action and placing mental disorders on top of the policy priority list.

Our findings also indirectly reveal that simply selecting one or two disorders as a target might not contribute effectively to change from a public health perspective. Rather, concerted action is needed from a broader perspective that considers the onset and the course of all disorders over the lifespan addressed in a coordinated manner, including the full spectrum of disorders in children and adolescents, adults, and the elderly. Tendencies to single out the most frequent, the seemingly most severe and dramatic presentations, and neglecting what might be perceived as "less severe" and significant, might lead neither to improved models in basic and clinical research nor to designing more effective care and intervention strategies. There is strong evidence, including our reviewed studies with a longitudinal component (i.e. de Graaf et al., 2011; Kessler et al., 2011, Beesdo et al., 2010, 2009), that the majority of people with mental disorders have had their first onset in childhood or adolescence, rarely remit spontaneously, but have substantially increased risk for a number of temporarily secondary disorders. These longitudinal patterns are reflected in the cross-sectional epidemiological studies as co- or even multi-morbidity. This apparently not random developmental pattern is not only associated with increasingly more malignant patterns of psychosocial dysfunctions and disability, but contributes to the immense disability burden of mental disorders. Such developmental pathways seem to indicate the existence of critical trajectories for certain types of disorders that might be chosen as potentially promising targets for interventions and, thus, might have significant value for improved causal models.

From this perspective, the frequent strategy of overstressed health care systems to care predominantly for the most severe - which typically implies for mental disorders those that 
are already quite advanced on their way to severe co- and multi-morbid suffering - seems to be inadequate (Kessler et al., 2003). A higher impact could be expected from stringent early detection and early treatment before more severe expression occurs. In this respect, our findings of high rates of anxiety, childhood and adolescent disorders provide important clues for what types of disorders might be most promising targets.

Our findings hopefully also contribute to correcting misconceptions and stigma. In particular the notion that mental disorders simply reflect poor coping with everyday problems in living, confined to a few people. It is important to highlight that our data do not reflect "mental health problems" as frequently assumed. Instead, our data refer without exceptions to clinically highly relevant specific disorders, determined by the use of standardized diagnostic assessments with explicit diagnostic criteria as defined in the official diagnostic classification system. Being almost exclusively based on the DSM-IIIR and DSM-IV criteria, this report only counts people as having mental disorders when all criteria are met, including the mandatory criteria of duration, severity, as well as dysfunction in psychosocial functioning and disability. The existence of such diagnostic manuals and procedures is typically not known and appreciated. Lay persons, the public, and even many clinicians and researchers might be surprised and skeptical both about our 38\% estimate and the large number of disorders included. This might be due to limited knowledge, negative attitudes, and potentially to misconceptions about the nature of mental disorders. Most lay people are unaware of the full spectrum of mental disorders, being typically only informed about diagnoses like depression, alcohol and drug dependence, and schizophrenia. We hope that our report will be instrumental in changing this.

However, even mental health specialists might be surprised by our prevalence tables. This is because in their everyday practice they see quite different patterns of patients due to factors like diagnosis-specific helpseeking behavior, severity of the condition, or specializations of the clinician.

We hope that our findings will have an impact on the public, clinicians, and policy makers leading to different attitudes and understandings of mental disorders as a core health challenge. Understanding that mental disorders and neurological disorders are disorders of the brain, bound to healthy brain functions as the most complex human organ, occurring in many forms with different causes, symptoms, and patterns, will be a major first step for the future. Proving and communicating that these disorders are treatable by a range of treatment options will be another core challenge.

\subsection{Health care utilization and treatment implications}

The availability of the six-country study ESEMeD/MHEDEA 2000 Investigators (2004c) provides benchmark data, that appear by and at large consistent with several individual national and regional studies (Bijl and Ravelli, 2000b; Bijl et al., 2003; Jacobi et al., 2004a,b; ten Have et al., 2004; Wittchen, 2000). According to these convergent findings, only one out of two patients with a mental disorder has ever received some professional attention. Among those with at least one contact, the vast majority is seen only in primary care. There is little doubt that only about one in four of all subjects with mental disorders receive any professional mental health help, and even fewer receive notionally adequate (10\%) mental health care by drugs or psychotherapy. Even in the more comprehensive health care systems with access free of charge to psychotherapy, such as in Germany (Jacobi et al., 2004a), the situation is not markedly different. Thus, we concluded in 2005 (Wittchen and Jacobi, 2005) that across the EU there seems to be a substantial degree of unmet treatment needs. There are 
some indications that the type and the degree of unmet needs vary widely by region and country (ESEMeD/MHEDEA, 2000 Investigators, 2004c), and that only some disorders, such as depression, are likely to receive any professional attention and treatment (Bijl et al., 2003). Our 2005 health economic analyses highlighted that mental disorders are extremely costly, not because of high direct treatment costs, but because of indirect costs. Compared to many somatic diseases, the categories of costs are very different with disproportionally high indirect cost items (sick days and disability, early retirement), and relatively low direct costs of health care (low expenditures for diagnostic measures, treatment and care), raising the question of whether the indirect cost burden could be substantially reduced by effective increases in direct costs.

Our current report has revealed that the situation summarized for 2005 has not substantially changed. This is supported by longitudinal studies, in particular the NEMESIS-2 study (de Graaf et al., 2010, 2011).

Part of the explanation why it is apparently so difficult to progress may be that treatment for many disorders is variable and various, ranging from physical (i.e. electroconvulsive therapy) and drug treatment to various forms of psychological therapies as well as psychosocial and counseling interventions. Treatment providers are psychiatrists and neurologists, general practitioners or psychotherapists, with either a medical or a psychological background, and a range of other human service providers, such as social workers whose work may be mostly syndrome-specific. In many countries the situation is complicated by the diversity of cost and reimbursement institutions (governmental and private insurance, pension funds, internal sickness funds in companies etc.; Knapp et al., 2007). The fragmentation of disciplines and concepts in the mental health treatment system continues to be a major challenge.

Kessler and Üstün (2008) recently summarized the unmet need for treatment of mental disorders under three major headings. First only a minority of people with mental disorders, even in countries with the best health care systems, are receiving treatment. The second is that even though a higher proportion of chronic cases eventually obtain treatment, substantial delays in obtaining treatment are pervasive with long time lapses, typically averaging years. The third is the questionable quality of most treatments. Once provided, it is often inadequate in relation to minimal standards published in treatment guidelines. The authors highlight that the third component is particularly critical because the other components become, to some extent, irrelevant unless treatment meets minimal standards of adequacy. This consideration raises concerns particularly with regard to the frequent awareness and screening campaigns conducted in the recent years.

\subsection{Disability}

The available data (ESEMeD/MHEDEA, 2000 investigators, 2004b; Bijl et al., 2003; Jacobi et al., 2004b) confirm the immense disability burden in terms of several crude (years lived with disability, work loss days etc.) and more sophisticated indicators (work productivity, quality of life etc.). Consistent with numerous earlier studies for specific diagnoses (Bijl and Ravelli, 2000a; Jacobi et al., 2004b; Greenberg et al., 1996, 1999; Kessler and Frank, 1997; Rice and Miller, 1998; Spijker et al., 2004; Wittchen, 2002) and expert-based WHO projections (i.e. Murray and Lopez, 1996; Olesen and Leonardi, 2003), there is thus little doubt that mental disorders rank together as the quantitatively most disabling group of all medical disorders. This is because of the critical combination of their high prevalence and the diagnosis-specific associated impairments and disabilities. Many mental disorders, in particular anxiety, substance, and somatoform disorders start as early as in childhood, having 
typically adverse effects on further neurocognitive development, such as with regard to school and academic achievement, social functioning and social integration, that might persist throughout the lifespan or at least have an enduring impact.

The DALY analyses presented in this report provide considerably improved measures that are specific for the EU and that should be used as a future standard reference.

The new estimates

- confirm that disorders of the brain are the major contributor to the total EU disease burden;

- reveal that depression - in contrast to previous projections - is already now the most important single contributor to the total disease burden;

- show that there are tremendous diagnosis-specific differences, and highlight that even seemingly "less serious" disorders are associated with a substantial degree of disability; and

- confirm the existence of substantially different disability differences between females and males.

However, the disability data used for our examination also raise serious concerns because they evidently do not reflect the full range of mental disorders that should have been considered. Many childhood/adolescent disorders, and many prevalent types of anxiety and somatoform disorders aswell as neurological disorders (Leonardi, 2010; Leonardi et al., 2010), for example, are not at all or obviously not adequately accounted for. It is further highly questionable whether the residual category of "other neuropsychiatric disorders" accurately reflects their impact. Future DALY analyses must take a more comprehensive account of the full spectrum of disorders of the brain to ensure adequate representation of these disorders in the future.

\subsection{Epidemiological research needs}

Our findings also highlight several evident future needs in epidemiological and public health research:

- There is a strong need for greater coordination and even standardization of methods to improve further the quality and comparability of epidemiological data in the EU, extending the diagnostic range to cover simultaneously neurological and mental disorders. Greater harmonization of epidemiological standards in studies for mental and neurological disorders would allow to derive overall estimates of prevalence for disorders of the brain - not available at this point in time and overcome disciplinary fragmentation.

- Europe is characterized by an immense diversity of mostly national studies (single country or region) with a considerable degree of clinical and methodological sophistication. This "richness", however, has the considerable disadvantage of restricting the possibility of direct comparisons between countries and estimating prevalence across all EU countries (Fryers et al., 2004). Improved methods might also be instrumental to decide whether there are "true" and consistent differences in prevalence by country, as indirectly suggested by cross-national comparison data (The WHO World Mental Health Survey Consortium, 2004, ESEMed/MHEDEA, 2000 Investigators, 2004a). 
- There is a need for incidence longitudinal studies especially in defined age cohorts, for example in children and adolescents, that would provide better data for the onset, natural course and the identification of critical trajectories. Such data would provide better guidance for preventive trials, and targeted early interventions. This is particularly important for preventing the development of co- and multimorbidity, because earlier and more rapid treatment of a temporally primary disorder will prevent secondary comorbidity.

- There is also a strong and continued need for studies in the elderly that inform about the most prevalent mental disorders in old age, the complex developmental patterns of co- and multimorbidity between mental and neurological and other somatic diseases. Beyond providing much needed data about the natural course, trajectories and determinants of disorders of the brain in old age, the specific needs for interventions in this age group (RiedelHeller et al., 2006) should be determined more comprehensively.

- Most diagnoses of mental disorders cannot be directly equated with specific treatment needs. Thus there is a need for studies that include a wider range of information regarding treatment and intervention needs. On this basis clinically sensitive and economically feasible decision algorithms could be explored to determine what types of interventions should be assigned to which type of patient. These algorithms might go beyond the established diagnostic classes acknowledging additionally patterns of comorbidity, behavioral, medical, and developmental risks, instead of oversimplified measures of current "severity" or "impairment".

\section{Conclusion}

The results of this EU review are by and at large consistent with those of earlier international studies where a similar range of disorders is considered. However, we document that the true range of mental disorders is obviously considerably larger than the previously available "bestestimate" of $27 \%$ suggested in 2005 (Wittchen and Jacobi, 2005). The present survey has covered 27 diagnoses, adding 14 more core diagnoses of mental disorders arriving at a conservative estimate of $38.2 \%$. Thus, well over one third of the EU population during any given 12 month period suffers from mental disorders alone, most of which are not receiving any treatment.

The true size of "disorders of the brain" that includes a wider range of neurological disorders in addition to mental disorders is almost certainly even considerably larger. Methodological reasons and the fact that the overlap (comorbity) between mental and neurological could not be determined and accounted for with acceptable precision prohibited the derivation of an overall prevalence. The high prevalence of neurological disorders provides proof that our $38 \%$ estimate is at best a conservative, lower bound estimate for disorders of the brain. We conclude accordingly that the true size and burden of disorders of the brain in the EU has been significantly underestimated in the past. Concerted priority action is needed at all levels, including in particular substantially increased funding for basic, clinical and public health research in order to identify better strategies for improved prevention and treatment for disorders of the brain as the core health challenge of the 21 st century. 


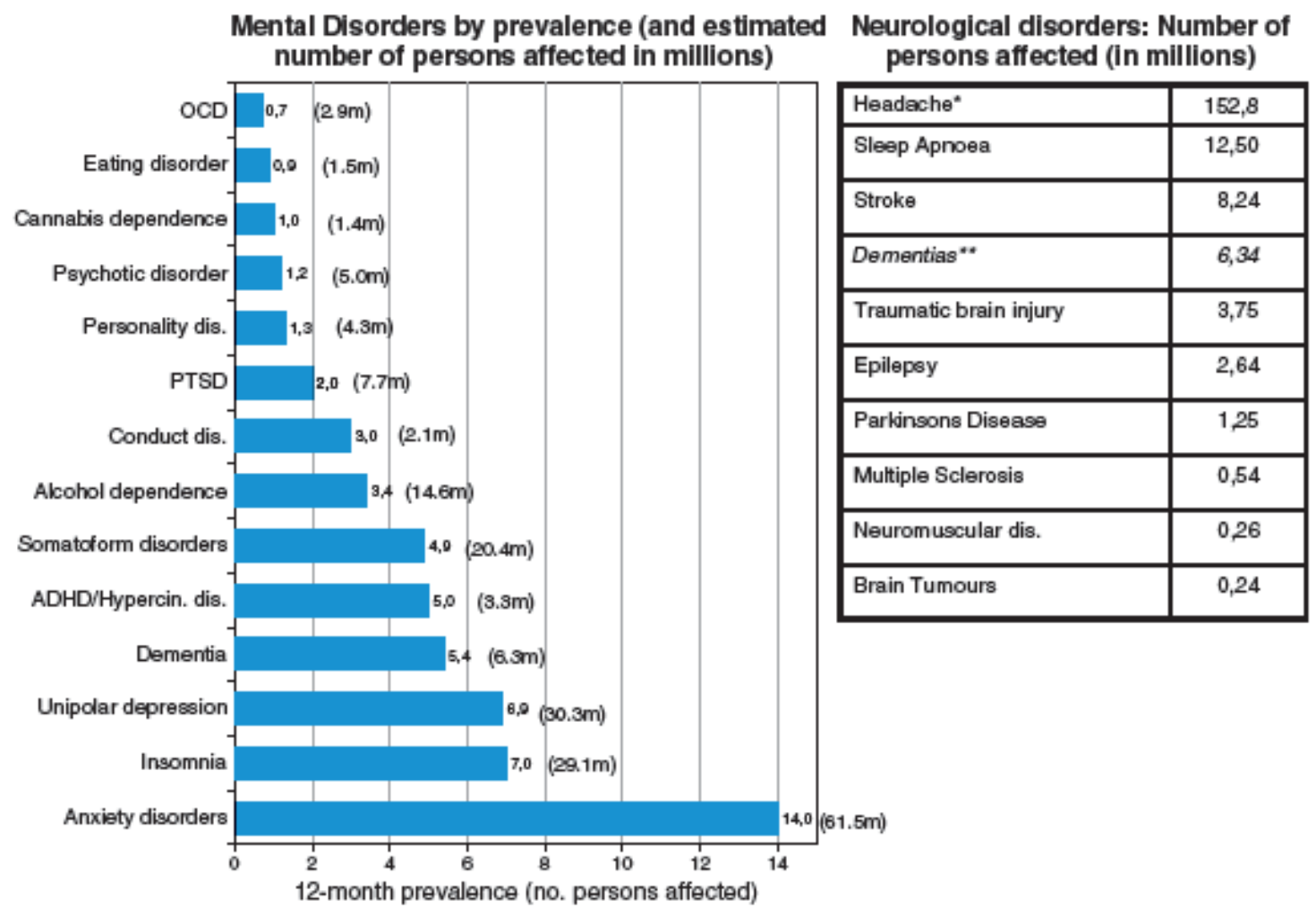

Fig. 1 Note 1: Except for dementia estimates for neurological disorders are not included in the overall prevalence estimate (") for mental disorders. Note 2: Only a few sellected neurological conditions conditions covered in the "Cost of Disorders of the Brain" project are listed here. Note 3: Several mental disorders presented in the text are not listed in the figure, because of space restrictions. (") Might overlap with somatoform disorders in mental disorders. (") Dementia is listed among mental and neurologic disorders.

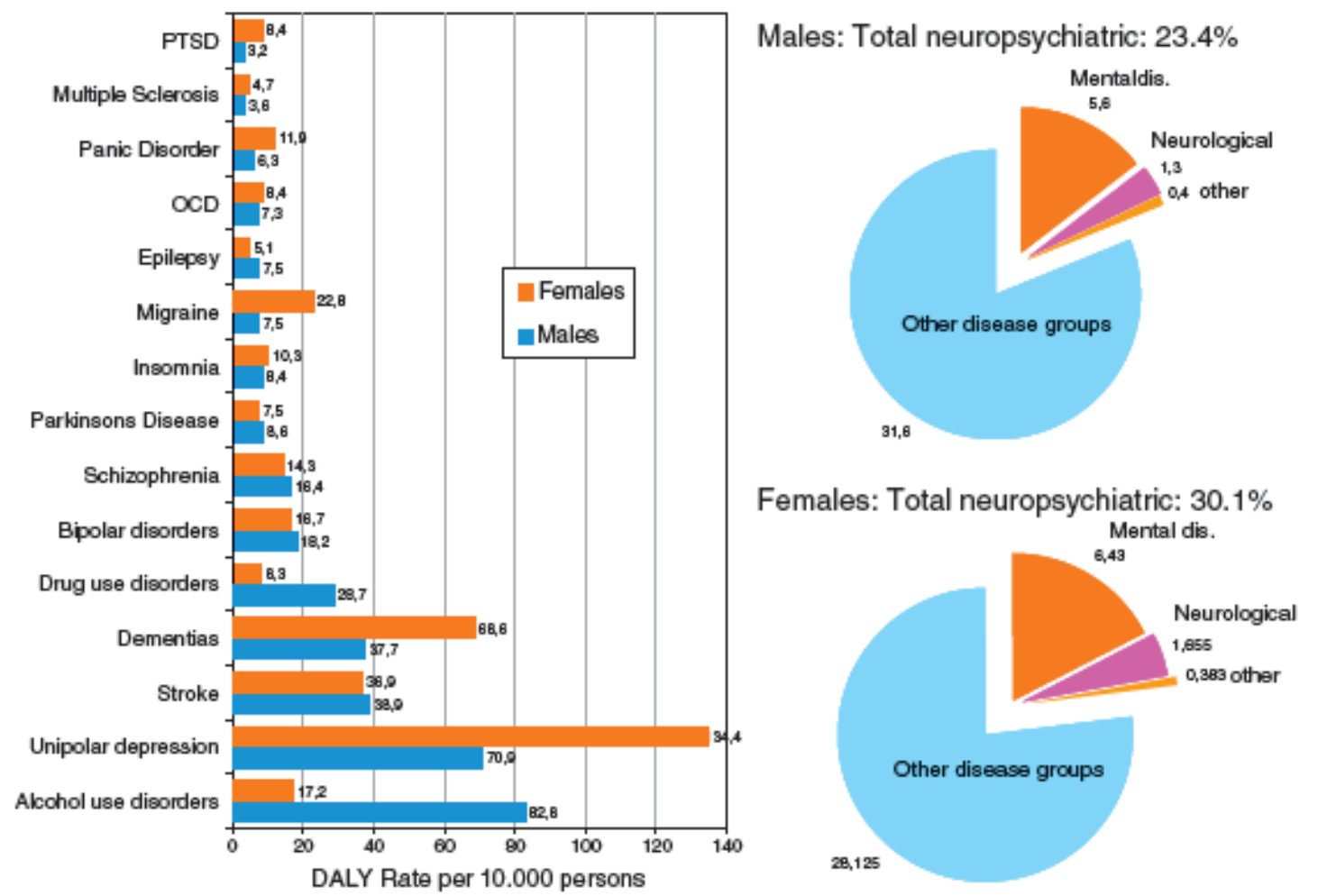

Fig. 2 Summary of DALY estimates. 
Table 1

Diagnoses ${ }^{\mathrm{a}}$ and studies included in the review.

\begin{tabular}{|c|c|c|c|}
\hline Disorders & $\begin{array}{l}\text { Age range } \\
\text { considered }\end{array}$ & $\begin{array}{l}\text { ICD-10 } \\
\text { codes }\end{array}$ & Studies/references \\
\hline \multicolumn{4}{|c|}{$\begin{array}{l}\text { A) Disorders already included in } 2005 \text { report } \\
\text { Substance use disorders }\end{array}$} \\
\hline Alcohol dependence & $15+$ & F10.2 & \multirow{3}{*}{ 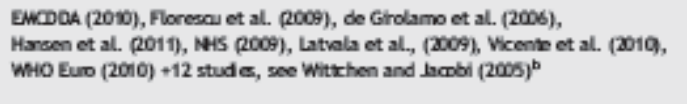 } \\
\hline Opioid dependence & $15-64$ & F11.2 & \\
\hline Cannabis dependence & $15-64$ & F12.2 & \\
\hline \multicolumn{4}{|l|}{ Psychotic disorders } \\
\hline $\begin{array}{l}\text { Schizophrenia } \\
\text { Other psychotic disorders }\end{array}$ & $\begin{array}{l}18+ \\
18+\end{array}$ & $\mathrm{F} 2 \mathrm{x}$ & 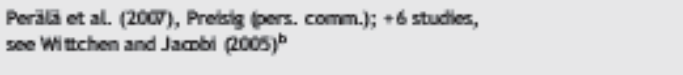 \\
\hline \multicolumn{4}{|l|}{ Mood disorders } \\
\hline Major depression & $14+$ & F32, F33 & \multirow{2}{*}{ 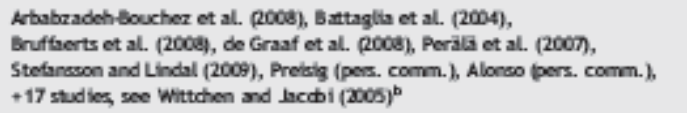 } \\
\hline Bipolar disorders & $18-65$ & F30, F31 & \\
\hline \multicolumn{4}{|l|}{ Anxiety disorders } \\
\hline Panic disorder & $14+$ & F41.0 & \multirow{4}{*}{ 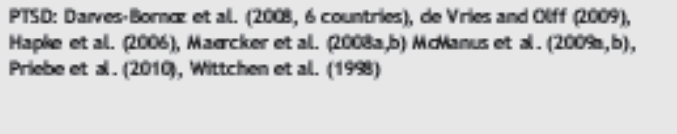 } \\
\hline Agoraphobia & $14+$ & $\mathrm{F} 40.0$ & \\
\hline Social phobia & $14+$ & $\mathrm{F} 40.1$ & \\
\hline GAD & $14+$ & F41.1 & \\
\hline Specific phobias & $14-65$ & $\mathrm{~F} 40.2$ & \multirow{3}{*}{ 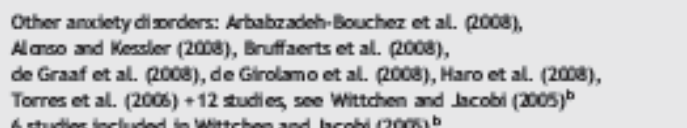 } \\
\hline OCD & $18+$ & $\mathrm{F} 42$ & \\
\hline PTSD & $14+$ & F43.1 & \\
\hline \multicolumn{4}{|l|}{ Eating disorders } \\
\hline Anorexia nervosa & $14-65$ & $\mathrm{~F} 50.0, \mathrm{~F} 50.1$ & \multirow[t]{2}{*}{ Preti iet al. $\left(2009,6\right.$ countries) +5 studies, see Wittchen and Jacobil $(2005)^{b}$} \\
\hline Bulimia nervosa & $14-65$ & $\mathrm{~F} 50.2, \mathrm{~F} 50.3$ & \\
\hline \multicolumn{4}{|c|}{ B) New diagnoses included since 2004} \\
\hline \multicolumn{4}{|c|}{ Childhood and adolescence disorders } \\
\hline Hyperkinetic disorders/ ADHD & $6-17$ & F90.x & \multirow{3}{*}{ 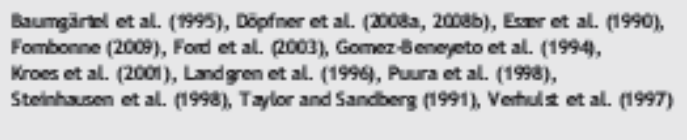 } \\
\hline Conduct disorder & $5-17$ & F91. $x$ & \\
\hline $\begin{array}{l}\text { Pervasive developmental } \\
\text { disorders/autism }\end{array}$ & $2-17$ & F84. $x$ & \\
\hline Mental retardation & $2-65$ & F70-F79 & Maulick et al. (2011; 17 studies fram Eurpe) \\
\hline \multicolumn{4}{|l|}{ Personality disorders (PD) } \\
\hline Dissocial PD ${ }^{c}$ & $18-65$ & $\mathrm{~F} 60.2$ & \multirow[t]{2}{*}{ Cold et al. (2006), Torgersen et al. (200) } \\
\hline Emotionally unstable $\mathrm{PD}^{\mathrm{c}}$ & $18-65$ & $\mathrm{~F} 60.3$ & \\
\hline \multicolumn{4}{|l|}{ Sleep disorders } \\
\hline Nonorganic insomnia & $18+$ & F51.x & \multirow{5}{*}{ 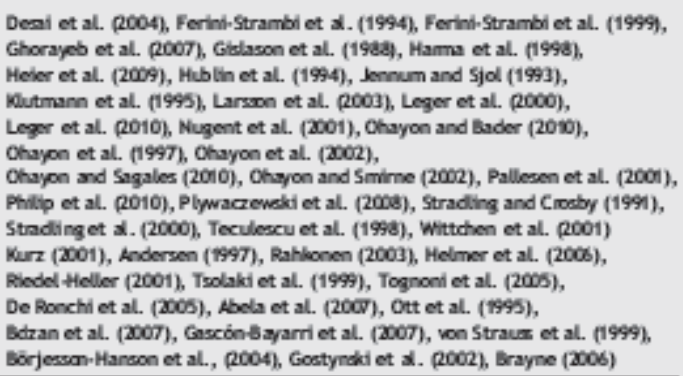 } \\
\hline Hypersomnia & $18+$ & G47.1 & \\
\hline Narcolepsy & $18+$ & G47.3 & \\
\hline Sleep apnea & $18+$ & G47.4 & \\
\hline Dementias & $60+$ & $\mathrm{F} 00-\mathrm{F} 03$ & \\
\hline
\end{tabular}


Table 2 Summary of prevalence studies (median) in mental disorders: best estimates and number of subjects in the EU affected (part t: diagnoses covered in 2005 report).

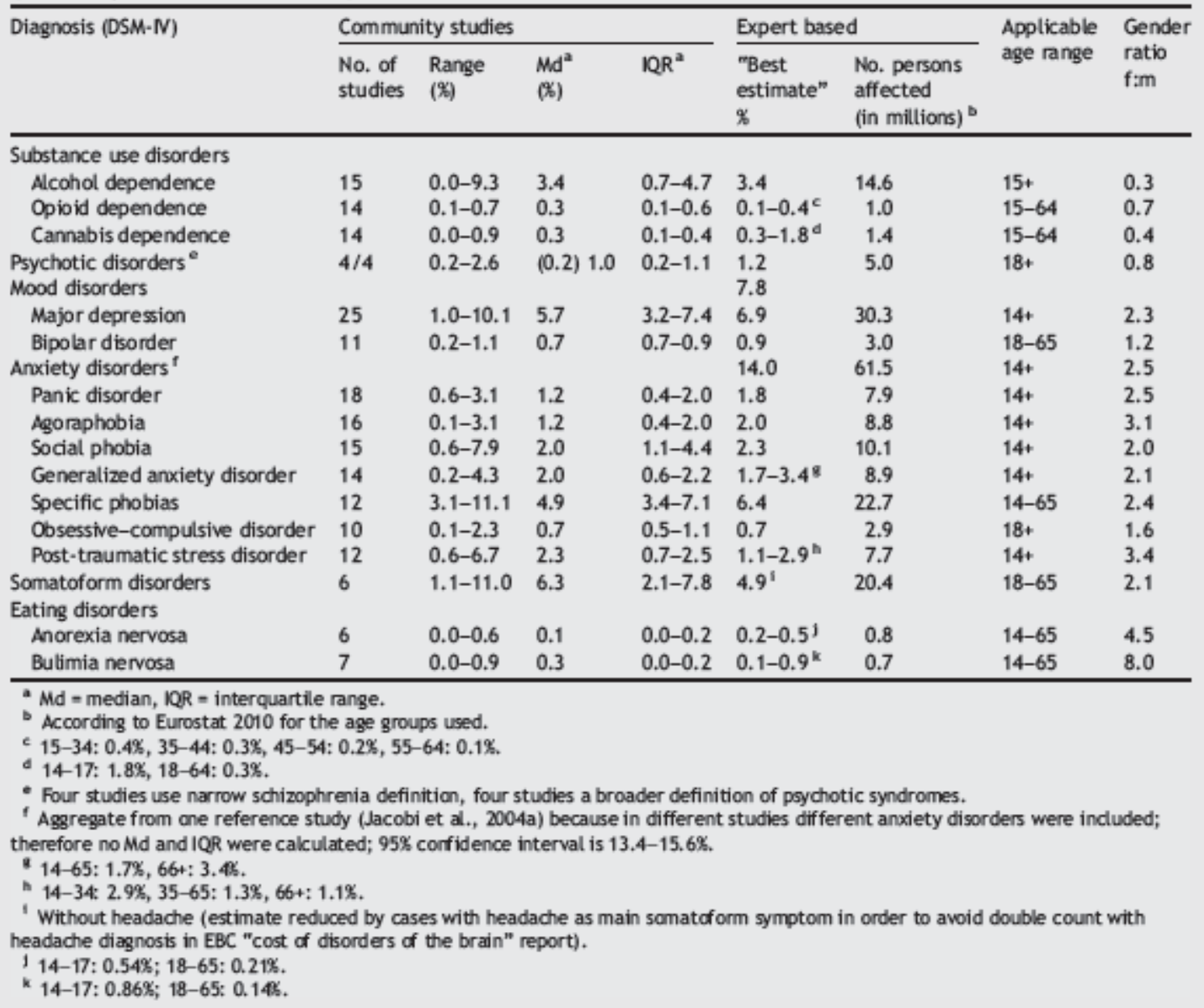

Table 3 Prevalence studies in mental disorders: best estimates and number of subjects in the EU affected (part II: new diagnoses (not in 2005 report)).

\begin{tabular}{|c|c|c|c|c|c|c|}
\hline Diagnosis (DSM-IV) & $\begin{array}{l}\text { No. of } \\
\text { studies }\end{array}$ & $\begin{array}{l}\text { Range } \\
(\%)\end{array}$ & $\begin{array}{l}\text { "Best } \\
\text { estimate" } \\
(\%)\end{array}$ & $\begin{array}{l}\text { No. persons } \\
\text { affected } \\
\text { (in millions) a }^{\text {a }}\end{array}$ & $\begin{array}{l}\text { Applicable } \\
\text { age range }\end{array}$ & $\begin{array}{l}\text { Gender } \\
\text { ratio } \\
\mathrm{f}: \mathrm{m}\end{array}$ \\
\hline \multicolumn{7}{|l|}{ Personality disorders (PD) } \\
\hline Bordertine PD & 2 & $0.7-0.7$ & 0.7 & 2.3 & $18-65$ & 0.5 \\
\hline Dissocial/antisocial PD & 2 & $0.6-0.7$ & 0.6 & 2.0 & $18-65$ & 0.2 \\
\hline \multicolumn{7}{|l|}{ Childhood and adolescent disorders } \\
\hline Hyperkinetic disorders/ADHD & 12 & $1.0-17.8$ & 5.0 & 3.3 & $6-17$ & 0.3 \\
\hline Pervasive developmental dis. & 19 & $0.3-1.8$ & 0.6 & 0.6 & $2-17$ & 0.25 \\
\hline Conduct disorders & 6 & $0.0-6.0$ & 3.0 & 2.1 & $5-17$ & 0.3 \\
\hline Mental retardation (IDD) & 17 & $0.4-1.4$ & 1.0 & 4.2 & $2-65$ & 0.8 \\
\hline \multicolumn{7}{|l|}{ Sleep disorders } \\
\hline Insomnia & 8 & $6.0-12.0$ & 7.0 & 29.1 & $18+$ & 2.0 \\
\hline Hypersomnia & 2 & $0.8-0.8$ & 0.8 & 3.1 & $18+$ & 1.0 \\
\hline Narcolepsy & 3 & $0.02-0.05$ & 0.02 & 0.1 & $18+$ & 1.0 \\
\hline Sleep apnoea & 14 & $1.3-4.0$ & 3.0 & 12.5 & $18+$ & 0.7 \\
\hline Dementia ${ }^{\circ}$ & 17 & n.a. ${ }^{c}$ & 5.4 & 6.3 & $60+$ & 1.6 \\
\hline
\end{tabular}


Table 4 Comparison of 2005 and 2011 estimates and overall number of cases affected by mental disorders in the EU (in millions).

\begin{tabular}{|c|c|c|c|c|}
\hline & \multicolumn{2}{|c|}{ Prevalence estimate } & \multicolumn{2}{|c|}{ No. of persons affected } \\
\hline & 2005 & 2011 & 2005 & 2011 \\
\hline & $\%(95 \% \mathrm{Cl})$ & $\%$ & Million & Million \\
\hline \multicolumn{5}{|l|}{ Group A: 2005 repart diagnoses } \\
\hline Alcohol dependence & $2.4(0.2-4.8)$ & 3.4 & $7.2(5.9-8.6)$ & 14.6 \\
\hline Opioid dependence (drug dep) & $0.5(0.1-0.6)$ & $0.1-0.4$ & $2.0(1.5-2.2)$ & 1.0 \\
\hline Cannabis dependence (drug dep) & See above & $0.3-1.8$ & See above & 1.4 \\
\hline Psychotic disorders & $0.8(0.2-2.0)$ & 1.2 & $3.7(2.8-5.4)$ & 5.0 \\
\hline Major depression & $6.9(4.8-8.0)$ & 6.9 & $18.4(17.2-19)$ & 30.3 \\
\hline Bipolar disorder & $0.9(0.5-0.9)$ & 0.9 & $2.4(1.7-2.4)$ & 3.0 \\
\hline Panic disorder & $1.8(0.7-2.2)$ & 1.8 & $5.3(4.3 .-5.3)$ & 7.9 \\
\hline Agoraphobia & $1.3(0.7-2.0)$ & 2.0 & $4.0(3.3-4.7)$ & 8.8 \\
\hline Social phobia & $2.3(1.1-4.8)$ & 2.3 & $6.7(5.4-9.3)$ & 10.1 \\
\hline Generalized anxiety dis. & $1.7(0.8-2.2)$ & $1.7-3.4$ & $5.9(5.3-6.2)$ & 8.9 \\
\hline Specific phobias & $6.4(3.4-7.6)$ & 6.4 & $18.5(14.4-18.6)$ & 22.7 \\
\hline OCD & $0.7(0.5-1.1)$ & 0.7 & $2.7(2.5-3.1)$ & 2.9 \\
\hline PTSD & - & $1.1-2.9$ & - & 7.7 \\
\hline Somatoform disorders ${ }^{d}$ & $6.3(2.1-7.8)$ & 4.9 & $18.9(12.7-21.2)$ & 20.4 \\
\hline Anorexia nervosa (eating dis.) & $0.4(0.3-0.7)$ & $0.2-0.5$ & $1.2(1.0-1.7)$ & 0.8 \\
\hline Bulimia nervosa (eating dis.) & See above & $0.1-0.9$ & See above & 0.7 \\
\hline Subtotal any Group A & $27.4 \%$ & $27.1 \%$ & 82.7 & 118.1 \\
\hline \multicolumn{5}{|l|}{ Group B: additional 2011 diagnoses } \\
\hline Borderline personality dis ${ }^{2}$ & - & 0.7 & - & 2.3 \\
\hline Dissocial personality dis ${ }^{a}$ & - & 0.6 & - & 2.0 \\
\hline Hyperkinetic dis./ADHD ${ }^{\circ}$ & - & $(5.0) 0.6$ & - & 3.3 \\
\hline Pervasive dev. dis./ autism & - & 0.6 & - & 0.6 \\
\hline Conduct disorders $^{\mathrm{B}}$ & - & $(3.0) 0.4$ & - & 2.1 \\
\hline Mental retardation & - & 1.0 & - & 4.2 \\
\hline Insomnia ${ }^{c}$ & - & $(7.0) 3.5$ & - & (29.1) 14.6 \\
\hline Hypersomnia & - & 0.8 & - & 3.1 \\
\hline Narcolepsy & - & 0.02 & - & 0.1 \\
\hline Sleep apnoea & - & 3.0 & - & 12.5 \\
\hline Dementias $^{\circ}$ & - & (5.4) 1.2 & - & 6.3 \\
\hline Total any Group B & - & 27.1 & & 51.0 \\
\hline Subtotal any adjusted & - & $11.1 \%$ & - & 46.7 \\
\hline Total $A$ and $B$ & $27.4 \%$ & $38.2 \%$ & 82.7 & 164.8 \\
\hline
\end{tabular}

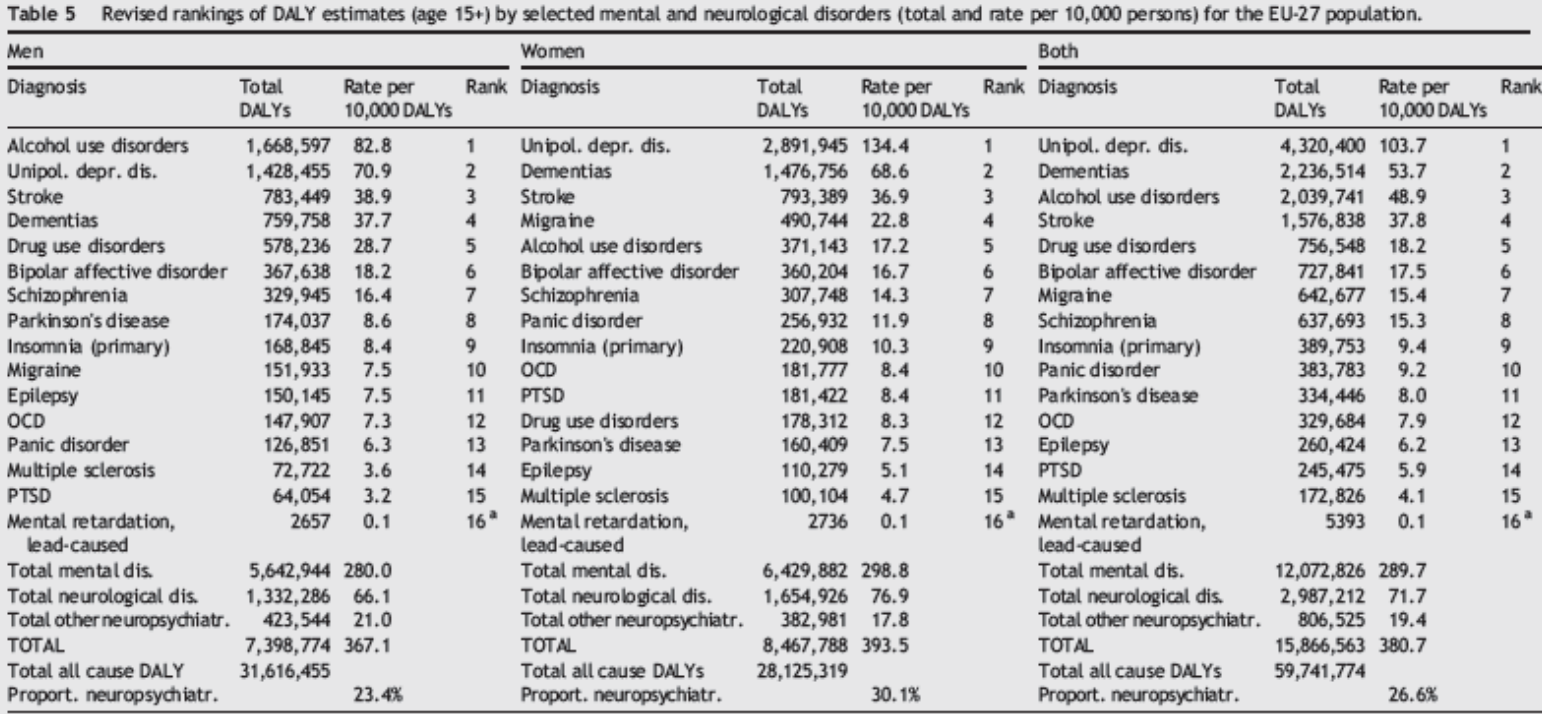

- DALYs due tolead coused mental retardation represent only a small froction of the burden attributable to mental retardation. 


\section{Role of the funding source}

This paper was commissioned by the European College of Neuropsychopharmacology (ECNP) who provided grant support to the Technische Universitaet Dresden in the context of European Brain Council (EBC) Task Force project on "Size and Burden and Cost of Disorders of the Brain". The overall Task Force project received unrestricted educational grant support by H. Lundbeck A/S as well as financial support by the European Federation of Neurological Societies. The funding agencies had no further role in the study design, collection of data, analysis, interpretation and the preparation of this manuscript.

\section{Contributors}

See below under acknowledgements.

\section{Conflict of interest}

None of the authors have conflicts of interest associated with the work reported in this paper.

\section{Acknowledgements}

This paper was prepared in the framework of the European College of Neuropsychopharmacology (ECNP) and European Brain Council (EBC) Task Force project on "Size and Burden and Cost of Disorders of the Brain in Europe 2010". The data summarized in this report provide the essential input for the $2011 \mathrm{EBC}$ (www. europeanbraincouncil.org) initiative "Cost of Disorders of the Brain in Europe" (CDBE; steering committee: Jes Olesen, Bengt Jönsson, Hans-Ulrich Wittchen). The support and assistance of many colleagues are acknowledged.

Overall coordination of the project was performed by Anders Gustavsson and the other members of the Steering Board (Jes Olesen, Bengt Jönsson, Hans-Ulrich Wittchen). Data collection for epidemiological issues in mental disorders was coordinated by the Institute of Clinical Psychology and Psychotherapy, Technische Universität Dresden (Frank Jacobi, Hans-Ulrich Wittchen), with the following diagnostic panels: substance use disorders (chaired by Jürgen Rehm, Roland Simon), psychotic disorders (Hans-Ulrich Wittchen, Jim van Os), mood disorders (Jordi Alonso, Martin Preisig), anxiety disorders (Christer Allgulander, Carlo Faravelli, Frank Jacobi, Andreas Maercker, Hans-Ulrich Wittchen), somatoform disorders (Roselind Lieb), eating disorders (Hans-Ulrich Wittchen), personality disorders (Frank Jacobi), childhood/adolescence and developmental disorders (Hans-Christoph Steinhausen), mental retardation/intellectual disability disorders (Luis Salvador-Carulla), sleep disorders (Poul Jennum), and dementias (Laura Fratiglioni). Further neurological panels were: multiple sclerosis (Maura Pugliatti), movement disorders (Richard Dodel), brain tumor (Brigitte Schlehofer), brain trauma (Pieter E. Vos), stroke (Tobias Kurth), headaches (Lars Jacob Stovner), epilepsy (Ettore Beghi), and neuromuscular disorders (Peter van den Bergh, David Hilton-Jones). DALY calculations provided by Jürgen Rehm.

Additionally, the following experts provided support in at least one of the work steps: Stefanie Drabsch (University of Florence, Italy), Manfred Döpfner (University of Cologne, Germany), Simon Forstmeier (University of Zürich, Switzerland), Andrea Gabilondo (Generalitat de Catalunya, Barcelona, Spain), Andrew Gloster (Technische Universität Dresden, Germany). Michael Höfler (Technische Universität Dresden, Germany), Corinna Jacobi (Technische 
Universität Dresden, Germany), Linus Jönsson (i3 innovus, Stockholm, Sweden), Korinna Karampampa (i3 innovus, Stockholm, Sweden), Danica Klempova (EMCDDA, Lisbon, Portugal), Gunther Meinlschmidt (University of Basel, Switzerland), Amir Musayev (i3 innovus, Stockholm, Sweden), Jayadeep Patra (Centre for Addiction and Mental Health, Toronto, Canada), Rafael Martínez-Leal, Jose García-Ibáñez, and Francisco Aguilera (Fundació Villablanca Reus, Spain), Peter van den Bergh (The Université catholique de Louvain, Belgium), Julian Vicente (EMCDDA, Lisbon, Portugal), Frank Verhulst (Erasmus Medical Center - Sophia Children's Hospital, Rotterdam, Netherlands), Weili Xu (Karolinska Institutet, Stockholm).

The authors would like to thank the experts for participating in commenting on the prevalence data for their countries: Austria: Johannes Wancata (Universitätsklinik für Psychiatrie, Vienna); Belgium: Julien Mendlewicz, (Hospital Erasme ULB, Department of Psychiatry, Brussels); Bulgaria: Hristo Hinkov (Department of Global Mental Health, National Center for Public Health Protection, Sofia); Cyprus: Ioanna Katsounari (The Chicago School Of Professional Psychology, Chicago); Czech Republic: Cyril Höschl (Prague Psychiatric Center, Prague); Denmark: Povl Munk-Jörgensen (Aalborg Psychiatric Hospital, Aalborg); Estonia: Eduard Maron (University of Tartu, Tartu); Finland: Erkki Isometsä (Institute of Clinical Medicine, Helsinki); France: Jean-Pierre Lèpine (Hôpital Fernand Widal, Paris); Greece: Petros Skapinakis (School of Medicine, Ioannina); Hungary: Zoltan Rihmer (National Institute for Psychiatry and Neurology, Budapest); Iceland: Jon G. Stefánsson (LandspitalinnUniversity Hospital, Reykjavík); Ireland: Donna Tedstone Doherty (Health Research Board, Dublin); Italy: Carlo Faravelli (Department of Neurology and Psychiatry, University of Florence, Florence); Latvia: Elmārs Rancāns (Latvian Academy of Medicine, Riga); Lithuania: Gintautas Daubaras (Mental Health Center, Vilnius), Arunas Germanavicius (Vilnius University, Vilnius); Netherlands: Ron de Graaf (Trimbos-Instituut, Utrecht); Norway: Kari Ann Leiknes (University of Oslo, Oslo); Romania: Bogdan Ioan Voinescu (University of Medicine and Pharmacy, Cluj-Napoca); Slovakia: Alexandra Brazinova (International Neurotrauma Research Organisation, Vienna); Slovenia: Mojca Dernovsek (Educational and Research Institute Ozara, Ljubljana); Spain: Jordi Alonso (IMIM - Hospital del Mar Research Institute, Barcelona); Sweden: Christer Allgulander (Karolinska Institutet, Stockholm); Switzerland: Martin Preisig (University of Lausanne, Prilly-Lausanne); United Kingdom: Traolach Brugha (Leicester General Hospital).

\section{References $^{5}$}

- Abela, A., Mamo, J., Aquilina, C., et al., 2007. Estimated prevalence of dementia in the Maltese Islands. Malta Med. J. 19, 23.

- Alonso, J., Kessler, R., 2008. Prevalence and treatment of mental disorders in Germany: results from the European study of the epidemiology of mental disorders (ESEMeD) survey. In: Kessler, Üstun (Eds.), The WHO World Mental Health Surveys: Global Perspectives on the Epidemiology of Mental Disorders. Cambridge University Press, New York, pp. 331-345.

- American Psychiatric Association, 1980. Diagnostic and Statistical Manual of Mental Disorders, 3rd ed. American Psychiatric Association, Washington, DC.

- American Psychiatric Association, 1987. Diagnostic and Statistical Manual of Mental Disorders. (rev.) third ed. American Psychiatric Association, Washington, DC.

- American Psychiatric Association, 1994. Diagnostic and Statistical Manual of Mental Disorders, 4th ed. American Psychiatric Association, Washington, DC.

\footnotetext{
${ }^{5}$ References with an * refer to publications and studies cited in Table 1.
} 
- Andersen, K., 1997. Prevalence of very mild to severe dementia in Denmark. Acta Neurol. Scand. 96, 82-87.

- Andlin-Sobocki, P., Olesen, J., Wittchen, H.-U., Jönsson, B., 2005. Cost of disorders of the brain in Europe. Eur. J. Neurol. 12, 1-27.

- *Angst, J., Gamma, A., Gastpar, M., Lépine, J.-P., Mendlewicz, J., Tylee, A., 2002. Gender differences in depression. Eur. Arch. Psy. Clin. N. 252, 201-209.

- *Angst, J., Gamma, A., Endrass, J., Goodwin, R., Ajdacic, V., Eich, D., Rössler, W., 2004. Obsessive-compulsive severity spectrum in the community: prevalence, comorbidity, and course. Eur. Arch. Psy. Clin. N. 254, 156-164.

- *Ansseau, M., 1999. Ėpidémiologie des troubles Psychiatiques dans la Province de Luxembourg. Brochure editée par la plate-forme de concertation psychiatrique de la Provence de Luxembourg.

- Arbabzadeh-Bouchez, S., Gasquet, I., Kovess-Masfety, V., Negre-Pages, L., Lépine, J.P., 2008. The prevalence of mental disorders and service use in France: results from a National Survey 2001-2002. In: Kessler, Üstun (Eds.), The WHO World Mental Health Surveys: Global Perspectives on the Epidemiology of Mental Disorders. Cambridge University Press, New York, pp. 305-330.

- *Arnarson, E.Ö., Gudmundsdottir, A., Boyle, G.J., 1998. Six-month prevalence of phobic symptoms in Iceland: an epidemiological postal survey. J. Clin. Psychol. 54, 257-265.

- *Ayuso-Mateos, J.L., 2001. Depressive disorders in Europe: prevalence figures from the ODIN study. Br. J. Psychiatry 179, 308-316.

- *Baruffol, E., 1993. Anxiety, depression, somatization and alcohol abuse. Prevalence rates in a general Belgian community sample. Acta Psychiatr. Belg. 93, 136-153.

- Battaglia, A., Dubini, A., Mannheimer, R., Pancheri, P., 2004. Depression in the Italian community: epidemiology and socioeconomic implications. Int. Clin. Psychopharmacol. 19, 135-142.

- Baumgärtel, A., Wolraich, M.L., Dietric, M., 1995. Comparison of diagnostic criteria for attention deficit disorders in a German elementary school sample. J. Am. Acad. Child Adolesc. Psychiatry 34, 629-638.

- Bdzan, L.B., Turczyński, J., Szabert, K., 2007. Prevalence of dementia in a rural population [Article in Polish]. Psychiatr. Pol. 41 (2), 181-188 (Mar-Apr).

- *Becker, E.S., Türke, V., Neumer, S., Soeder, U., Krause, P., Margraf, J., 2000. Incidence and prevalence rates of mental disorders in a community sample of young women: results of the "Dresden Study". In: Manz, R., Kirch, W. (Eds.), Public Health Research and Practice: Report of the Public Health Research Association Saxony II. Roederer, Regensburg, pp. 259-291.

- Beesdo, K., Höfler, M., Leibenluft, E., Lieb, R., Bauer, M., Pfennig, A., 2009. Mood episodes and mood disorders: Patterns of incidence and conversion in the first three decades of life. Bipolar Disorders 11, 637-649.

- Beesdo, K., Pine, D.S., Lieb, R., Wittchen, H.U., 2010. Incidence and risk patterns of anxiety and depressive disorders and categorization of Generalized Anxiety Disorder. Arch. Gen. Psychiatry 67 (1), 47-57.

- Berr, C., Wancata, J., Ritchie, K., 2005. Prevalence of dementia in the elderly in Europe. Eur. Neuropsychopharmacol. 15 (4), 463-471.

- Berwick, D.M., Murphy, J.M., Goldman, P.A., 1991. Performance of a five item mental health screening test. Med. Care 29, 169-176.

- *Bijl, R.V., Ravelli, A., van Zessen, G., 1998. Prevalence of psychiatric disorder in the general population: results of the Netherlands Mental Health Survey and Incidence Study (NEMESIS). Soc. Psych. Psych. Epid. 33, 587-595.

- Bijl, R.V., Ravelli, A., 2000a. Current and residual functional disability associated with psychopathology: findings from the Netherlands Mental Health Survey and Incidence Study (NEMESIS). Psychol. Med. 30, 657-668.

- Bijl, R.V., Ravelli, A., 2000b. Psychiatric morbidity, service use, and need for care in the general population: results of The Netherlands Mental Health Survey and Incidence Study. Am. J. Public Health 90, 602-607. 
- Bijl, R.V., de Graaf, R., Hiripi, E., Kessler, R.C., Kohn, R., Offord, D.R., Üstün, T.B., Vicente, B., Vollebergh,W.A.M., Walters, E.E., Wittchen, H.-U., 2003. The prevalence of treated and untreated mental disorders in five countries. Health Aff. 22, 122-133.

- Börjesson-Hanson, A., Edin, E., Gislason, T., Skoog, I., 2004. The prevalence of dementia in 95 year olds. Neurology 63 (12), 2436-2438 Dec 28.

- Brayne, C., 2006. Incidence of dementia in England and Wales: the MRC Cognitive Function and Ageing Study. Alzheimer Dis. Assoc. Disord. 20 (3 Suppl. 2), S47-S51 Jul-Sep.

- Bruffaerts, R., Bonnewyn, A., Demyttenaire, K., 2008. Metal Health in Belgium: Current Situation and future perspectives. In: Kessler, R., Üstün, B. (Eds.), The WHO World Mental Health Surveys: Global Perspectives on the Epidemiology of Mental Disorders. Cambridge University Press, New York, pp. 279-304.

- Brugha, T.S., McManus, S., Bankart, J., Scott, F., Purdon, S., Smith, J., Bebbington, P., Jenkins, R., Meltzer, H., 2011. Epidemiology of autism spectrum disorders in adults in the community in England. Arch. Gen. Psychiatry 68, 459-466.

- Campenhausen, S., Bornschein, B., Wick, R., Bötzel, K., Sampaio, C., Poewe, W., Oertel, W., Siebert, U., Berger, K., Dodel, R., 2005. Prevalence and incidence of Parkinson's disease in Europe. Eur. Neuropsychopharmacol. 15 (4), 473-490.

- Coid, J., Yang, M., Tyrer, P., 2006. Prevalence and correlates of personality disorder in Great Britain. Br. J. Psychiatry 188, 423-431.

- Collins, P.Y., Patel, V., Joestl, S.S., et al., 2011. Grand challenges in global mental health. Nature 475 (7354), 27.30.

- Corrigan, P., 2004. How stigma interferes with mental health care. Am. Psychol. 59 (7), 614 625.

- Darves-Bornoz, J.M., Alonso, J., de Girolamo, G., de Graaf, R., Haro, J.M., Kovess-Masfety, V., et al., 2008. Main traumatic events in Europe: PTSD in the European study of the epidemiology of mental disorders survey. J. Trauma. Stress 21, 455-462.

- de Girolamo, G., Polidori, G., Morosini, P., Scarpino, V., Reda, V., Serra, G., et al., 2006. Prevalence of common mental disorders in Italy: results from the European Study of the Epidemiology of Mental Disorders (ESEMeD). Soc. Psychiatry Psychiatr. Epidemiol. 41, 853-861.

- de Girolamo, G., Morosini, P., Gigantesco, A., Delmonte, S., Kessler, R., 2008. The prevalence of mental disorders and service use in Italy: results from the National Health Survey 2001-2003. In: Kessler, L., Üstun, M. (Eds.), Cambridge University Press,NewYork, pp. 364-387.

- de Graaf, R., Ormel, J., ten Have, M., Burger, H., Buist-Bouwman, M., 2008. Mental Disorders and Service Use in the Netherlands: Results from the European Study of the Epidemiology of Mental Disorders (ESEMeD). In: Kessler, L., Üstun, M. (Eds.), The WHO World Mental Health Surveys: Global Perspectives on the Epidemiology of Mental Disorders. Cambridge University Press, New York, pp. 388-405.

- de Graaf, R., ten Have, M., van Dorsselaer, S., 2010. The Netherlands Mental Health Survey and Incidence Study-2 (NEMESIS-2): design and methods. Int. J. Methods Psychiatr. Res. 193, 125-141.

- de Graaf, R., Ten Have, M., van Gool, C., van Dorsselaer, S., 2011. Prevalence of mental disorders and trends from 1996 to 2009. Results from the Netherlands Mental Health Survey and Incidence Study-2. Soc. Psychiatry Psychiatr. Epidemiol. doi:10.1007/s00127-010-03348 .

- De Ronchi, D., Berardi, D., Menchetti, M., et al., 2005. Occurrence of cognitive impairment and dementia after the age of 60: a population-based study from Northern Italy. Dement. Geriatr. Cogn. Disord. 19 (2-3), 97-105.

- de Vries, G.J., Olff, M., 2009. The lifetime prevalence of traumatic events and posttraumatic stress disorder in the Netherlands. J. Trauma. Stress 22, 259-267.

- Desai, A.V., Cherkas, L.F., Spector, T.D., Williams, A.J., 2004. Genetic influences in selfreported symptoms of obstructive sleep apnoea and restless legs: a twin study. Twin Res 7 (6), 589-595 (Dec). 
- Döpfner, M., Görtz-Dorten, A., Lehmkuhl, G., 2008a. Diagnostik-System für psychische Störungen nach ICD-10 und DSM-IV für Kinder und Jugendliche - II. Testzentrale, Göttingen.

- Döpfner, M., Breuer, D., Wille, N., Erhart, M., Ravens-Sieberer, U., 2008b. How often do children meet ICD-10/DSM-IV criteria of attention deficit-/hyperactivity disorder and hyperkinetic disorder? Parent-based prevalence rates in a national sample - results of the BELLA study. Eur. Child Adolesc. Psychiatry 17 (Suppl. 1), 59-70.

- *Dubini, A., Mannheimer, R., Pancheri, P., 2001. Depression in the community: results of the first Italian survey. Int. Clin. Psychopharmacol. 16, 49-53.

- Durkin, M., 2002. The epidemiology of developmental disabilities in low-income countries. Ment. Retard. Dev. Disabil. Res. Rev. 8,206-211.

- EMCDDA, 2010. Annual Report 2010, the State of the Drugs Problem in Europe. Publications Office of the European Union.

- ESEMeD/MHEDEA 2000 Investigators, 2002. The European Study of the Epidemiology of mental Disorders (ESEMeD/MHEDEA 2000). Project: rationale and methods. Int. J. Methods Psychiatr. Res. 11, 55-67.

- *ESEMeD/MHEDEA 2000 Investigators, 2004a. Prevalence of mental disorders in Europe: results from the European Study of the Epidemiology of Mental Disorders (ESEMeD) project. Acta Psychiatr. Scand. 109 (suppl. 1), 21-27.

- ESEMeD/MHEDEA 2000 investigators, 2004b. Disability and quality of life impact of mental disorders in Europe: results from the European Study of the Epidemiology of Mental Disorders (ESEMeD) project. Acta Psychiatr. Scand., 109. Suppl. 1.

- ESEMeD/MHEDEA 2000 Investigators, 2004c. Use of mental health services in Europe: results from the European Study of the Epidemiology of Mental Disorders (ESEMeD) project. Acta Psychiatr. Scand. 109 (Suppl. 1), 47-54.

- Esser, G., Schmidt, H., Woerner, W., 1990. Epidemiology and course of psychiatric disorders in school age children: results of a longitudinal study. J. Child Psychol. Psychiatry 31, 243263.

- *Faravelli, C.,Abrardi,L., Bartolozzi,D., Cecchi,C., Cosci, F.,D'Adamo, D., Lo Iacono, B., Ravaldi, C., Scarpato, M.A., Truglia, E., Rossi Prodi, P.M.S., Ros, S., 2004. The Sesto Fiorentino Study: point and one year prevalences of psychiatric disorders in an Italian community sample using clinical interviewers. Psychother. Psychosom. 73, 226-234.

- Ferini-Strambi, L., Zucconi, M., Palazzi, S., Castronovo, V., Oldani, A., Della, M.G., et al., 1994. Snoring and nocturnal oxygen desaturations in an Italian middle-aged male population. Epidemiologic study with an ambulatory device. Chest 105 (6), 1759-1764 Jun.

- Ferini-Strambi, L., Zucconi, M., Castronovo, V., Garancini, P., Oldani, A., Smirne, S., 1999. Snoring \& sleep apnea: a population study in Italian women. Sleep 22 (7), 859-864 Nov 1.

- $\quad$ First, M.B., Gibbon, M., Spitzer, R.L., et al., 1997. Structured Clinical Interviews for DSM-IV Axis-II Personality Disorders. American Psychiatric Press, Washington, DC.

- Florescu, S.,Moldovan, M.,Mihaescu-Pintia, C., Ciutan,M., Sorel, G.E., 2009. The Mental Health Study. Romania 2007. Prevalence, severity, and treatment of 12-month DSM-IV disorders. Manag. Health 13, 23-31.

- Fombonne, E., 2009. Epidemiology of pervasive developmental disorders. Pediatr. Res. 65, 591-598.

- $\quad$ Ford, T., Goodman, R., Meltzer, H., 2003. The British Child and Adolescent Mental Health Survey 1999: the prevalence of DSM-IV disorders. J. Am. Acad. Child Adolesc. Psychiatry 42, 1203-1211.

- Fryers, T., Brugha, T., Morgan, Z., Smith, J., Hill, T., Carta, M., Lehtinen, V., Kovess, V., 2004. Prevalence of psychiatric disorder in Europe: the potential and reality of meta-analysis. Soc. Psychiatry Psychiatr. Epidemiol. 39, 899-905.

- Gascón-Bayarri, J., Reñé, R., Del Barrio, J.L., et al., 2007. Prevalence of dementia subtypes in El Prat de Llobregat, Catalonia, Spain: the PRATICON study. Neuroepidemiology 28 (4), 224-234. 
- Ghorayeb, I., Loundou, A., Auquier, P., Dauvilliers, Y., Bioulac, B., Tison, F., 2007. A nationwide survey of excessive daytime sleepiness in Parkinson's disease in France. Mov Disord 22 (11),1567-1572 Aug 15.

- Gislason, T., Almqvist, M., Eriksson, G., Taube, A., Boman, G., 1988. Prevalence of sleep apnea syndrome among Swedish men — an epidemiological study. J. Clin. Epidemiol. 41 (6), 571-576.

- Goldberg, D.P., Hillier, V.F., 1979. A scaled version of the general health questionnaire. Psychol. Med. 9, 139-145.

- Goldberg, D., Huxley, P., 1980. Mental illness in the community: the pathway to psychiatric care. Tavistock, London.

- Gomez-Beneyeto, M., Bonet, A., Catala, M.A., 1994. Prevalence of mental disorders among children in Valencia, Spain. Acta Psychiatr. Scand. 89, 352-357.

- Goncalves, D.C., Pachana, N.A., Byrne, G.J., 2011. Prevalence and correlates of generalized anxiety disorder among older adults in the Australian National Survey of Mental Health and Well-Being. J. Affect. Disord. 132, 223-230.

- Gostynski, M., Ajdacic-Gross, V., Gutzwiller, F., et al., 2002. Prevalence of dementia in the City of Zurich. Soz. Praventivmed. 47 (5), 330-335 (German).

- Grant, B.F., Hasin, D.S., Stinson, F.S., et al., 2004. Prevalence, correlates, and disability of personality disorders in the United States: results from the National Epidemiologic Survey on Alcohol and Related Conditions. J. Clin. Psychiatry 65, 948-958.

- Grant, B.F., Chou, S.P., Goldstein, R.B., et al., 2008. Prevalence, correlates, disability, and comorbidity of DSM-IV borderline personality disorder: results from the Wave 2 National Epidemiologic Survey on Alcohol and Related Conditions. J. Clin. Psychiatry 69 (4), $533-$ 545.

- $\quad$ Greenberg, P.E., Kessler, R.C., Nells, T.L., Finkelstein, S.N., Berndt, E.R., 1996. Depression in the workplace: an economic perspective. In: Feighner, J.P., Boyer, W.F. (Eds.), Selective Serotonin Reuptakers: Advances in Basic Research and Clinical Practice. Wiley, New York.

- Greenberg, P.E., Sisitsky, T., Kessler, R.C., Finkelstein, S.N., Berndt, E.R., Davidson, J.R.T., Ballenger, J.C., Fyer, A.J., 1999. The economic burden of anxiety disorders in the 1990s. J. Clin. Psychiatry 60, 427-435.

- *Hällström, T., Damström, T., Thakker, K., Forsell, Y., Lundber, I., Tinghög, P., 2003. The PART Study. A population based study of mental health in the Stockholm county: study design. Phase, 1. Samhällsmedicin, Stockholm (1998-2001).

- Hansen, A.B.G., Hvidtfeldt, U.A., Gronbaek, M., Backer, U., Nielsen, A.S., Tolstrup, J.S., 2011. The number of persons with alcohol problems in the Danish population. Scand. J. Public Health 39, 128-136.

- Hapke, U., Scumann, A., Rumpf, H.U., John, U., Meyer, C., 2006. Post-traumatic stress disorder. The role of trauma, pre-exicting psychiatric disorders, and gender. Eur. Arch. Psychiatry Clin. Neurosci. 256, 299-306.

- Harma, M., Tenkanen, L., Sjoblom, T., Alikoski, T., Heinsalmi, P., 1998. Combined effects of shift work and life-style on the prevalence of insomnia, sleep deprivation and daytime sleepiness. Scand J Work Environ Health 24 (4), 300-307 Aug.

- Haro, J.M., Arbabzadeh-Bouchez, S., Brugha, T.S., de Girolamo, D., Guyer,M.E., jin,,R., L'epine, J.P.,Mazzi, F.,Reneses,B.,Saiz,G.V., Sampson, N.A., Kessler, R., 2008. Concordance of the Composite International Diagnostic Interview Version 3.0 (CIDI 3.0) with standardized clinical assessments in the WHO World Mental Health Surveys. In: Kessler, Üstun (Eds.), The WHO World Mental Health Surveys: Global Perspectives on the Epidemiology of Mental Disorders. Cambridge University Press, New York, pp. 114-134.

- Heier, M.S., Evsiukova, T., Wilson, J., Abdelnoor, M., Hublin, C., Ervik, S., 2009. Prevalence of narcolepsy with cataplexy in Norway. Acta Neurol Scand 120 (4), 276-280 Oct.

- Helmer, C., Pérès, K., Letenneur, L., et al., 2006. Dementia in subjects aged 75 years or over within the PAQUID cohort: prevalence and burden by severity. Dement. Geriatr. Cogn. Disord. 22 (1), 87-94.

- Huang, Y., Kotov, R., de Girolamo, G., et al., 2009. DSM-IV personality disorders in the WHO World Mental Health Surveys. Br. J. Psychiatry 195, 46-53. 
- Hublin, C., Kaprio, J., Partinen, M., Koskenvuo, M., Heikkila, K., Koskimies, S., et al., 1994. The prevalence of narcolepsy: an epidemiological study of the Finnish Twin Cohort. Ann Neurol 35 (6),709-716 Jun.

- Jacobi, F., Wittchen, H.-U., Holting, C., Sommer, S., Lieb, R., Höfler, M., Pfister, H., 2002. Estimating the prevalence of mental and somatic disorders in the community: aims and methods of the German National Health Interview and Examination Survey. Int. J. Method. Psych. 11, 1-18.

- *Jacobi, F., Wittchen, H.-U., Hölting, C., Höfler, M., Müller, N., Pfister, H., Lieb, R., 2004a. Prevalence, comorbidity and correlates of mental disorders in the general population: results from the German Health Interview and Examination Survey (GHS). Psychol. Med. 34, 597611.

- Jacobi, F., Klose, M., Wittchen, H.-U., 2004b. Psychische Störungen in der Allgemeinbevölkerung: Inanspruchnahme von Gesundheitsleistungen und Ausfalltage. [Mental disorders in the community: Health care utilization and disability days]. Bundesgesundheitsblatt Gesundh. Forsch Gesundh. Schutz 47, 736-744.

- *Jenkins, R., Lewis, G., Bebbington, P., Brugha, T., Farrell, M., Gill, B., Meltzer, H., 1997. The National Psychiatric Morbidity surveys of Great Britain - initial findings from the household survey. Psychol. Med. 27, 775-789.

- Jennum, P., Sjol, A., 1993. Snoring, sleep apnoea and cardiovascular risk factors: the MONICA II study. Int J Epidemiol 22 (3), 439-444 Jun.

- Kessler, Üstün (Eds.), 2008. The WHO World Mental Health Surveys: Global Perspectives on the Epidemiology of Mental Disorders. Cambridge University Press, New York.

- Kessler, R.C., Andrews, G., Mroczek, D., Üstün, T.B., Wittchen, H.-U., 1998. The World Health Organization Composite International Diagnostic Interview Short-Form (CIDI-SF). Int. J. Method. Psych. 74, 171-185.

- Kessler, R.C., Cox, B.J., Green, J.G., et al., 2011. The effects of latent variables in the development of comorbidity among common mental disorders. Depression and Anxiety 28 (1), 29-39.

- Kessler, R.C., Frank, R.G., 1997. The impact of psychiatric disorders on work loss days. Psychol. Med. 27, 861-873.

- Kessler, R.C., Merikangas, K.R., Berglund, P., Eaton, W.W., Koretz, D.S., Walters, E.E., 2003. Mild disorders should not be eliminated from the DSM-V. Arch. Gen. Psychiatry 60, $1117-1122$.

- Klin, A., Lemish, D., 2008. Mental disorders stigma in the media: review of studies on production, content, and influences. J. Health Commun. 13, 434-449.

- Klutmann, M., Winkels, W., Simon, H., 1995. Incidence and probable detection of sleep apnea in a hospital internal medicine department. Pneumologie 49 (Suppl. 1), 142-144 Mar.

- Knapp, M., McDaid, D., Amaddeo, F., Constantopoulos, A., Oliveira,M., Salvador-Carulla, L., Zechmeister, I., MHEEN Group, 2007. Financing mental health care in Europe. J. Ment. Health 1616 (2), 167-180 C: ISPS\Documents and Settings \Usuario\Documents and Settings $\backslash$ Luis $\backslash$ EscritoriolusbSept107\title $\sim$ content $=\mathrm{t} 713432595 \sim \mathrm{db}=\mathrm{all} \sim \mathrm{tab}=$ issueslist $\sim$ branche $\mathrm{s}=16$.

- Knauper, B., Wittchen, H.U., 1994. Diagnosing major depression in the elderly - evidence for response bias in standardized diagnostic interviews. J. Psychiatr. Res. 28, 147-164.

- *Kringlen, E., Torgersen, S., Cramer, V., 2001. A Norwegian Psychiatric Epidemiological Study. Am. J. Psychiatry 158, 1091-1098.

- Kroenke, K., Spitzer, R.L., Williams, J.B., 2001. The PHQ-9: validity of a brief depression severity measure. J. Gen. Intern. Med. 16, 606-613.

- Kroes, M., Kalff, A.C., Kessels, A.G.H., Stevaert, J., Feron, F., van Sommeren, A., Hurks, P., Hendriksen, J., van Zeban, T., Rozendaal, N., Crolla, I., Troost, J., Jolles, J., Vles, J., 2001. Child psychiatric diagnoses in a population of Dutch schoolchildren aged 6 to 8 years. J. Am. Acad. Child Adolesc. Psychiatry 40, 1401-1409.

- Kurz, X., 2001. Dementia in Belgium: prevalence in aged patients consulting in general practice. Rev. Med. Liege 56 (12), 835-839 Dec. 
- $\quad$ Landgren, M., Pettersson, R., Kjellman, B., Gillberg, C., 1996. ADHD, DAMP and other neurodevelopmental/psychiatric disorders in 6-year-old children: epidemiology and comorbidity. Dev. Med. Child Neurol. 38, 891-906.

- Larsson, L.G., Lindberg, A., Franklin, K.A., Lundback, B., 2003. Gender differences in symptoms related to sleep apnea in a general population and in relation to referral to sleep clinic. Chest 124 (1), 204-211 Jul.

- Latvala, A., Tuulio-Henriksson, A., Perälä, J., Saarni, S., Aalto-Setälä, T., Aro, H., et al., 2009. Prevalence and correlates of alcohol and other substance use disorders in young adulthood: a population-based study. BMC Psychiatry 9 (9), 73.

- Leger, D., Guilleminault, C., Dreyfus, J.P., Delahaye, C., Paillard, M., 2000. Prevalence of insomnia in a survey of 12,778 adults in France. J. Sleep Res. 9 (1), 35-42 Mar.

- Leger, D., Partinen, M., Hirshkowitz, M., Chokroverty, S., Hedner, J., 2010. Characteristics of insomnia in a primary care setting: EQUINOX survey of 5293 insomniacs from 10 countries. Sleep Med. 11 (10), 987-998 Dec.

- Leiknes, K.-A., Finset, A., Moum, T., Sandanger, I., 2007. Current somatoform disorders in Norway: prevalence, risk factors and comorbidity with anxiety, depression and musculosketal disorders. Soc. Psychiatry Psychiatr. Epidemiol. 42, 698-710.

- Leonardi, M., 2010. Measuring health and disability: supporting policy development. The European MHADIE project. Disabil. Rehabil. 32 (Suppl. 1), S1-S8.

- Leonardi, M., Chatterji, S., Ayuso-Mateos, J.L., Hollenweger, J., Ustün, B., Kostanjsek, N.F., Newton, A., Björck-Åkesson, E., Francescutti, C., Alonso, J., Matucci, M., Samoilescu, A., Good, A., Cieza, A., Svestkova, O., Bullinger, M., Marincek, C., Burger, H., Raggi, A., Bickenbach, J.E., 2010. Integrating research into policy planning: MHADIE policy recommendations. Disabil. Rehabil. 32 (Suppl. 1), S139-S147.

- *Lepine, J.P., Gastpar, M., Mendlewicz, J., Tylee, A., 1997. Depression in the community: the first pan-European study DEPRES (Depression Research in European Society). Int. Clin. Psychopharmacol. 12, 19-29.

- *Lieb, R., Pfister, H., Mastaler, M.,Wittchen, H.-U., 2000a. Somatoform syndromes and disorders in a representative population sample of adolescents and young adults: prevalence, comorbidity and impairments. Acta Psychiatr. Scand. 101, 194-208.

- $\quad$ Lieb, R., Isensee, B., von Sydow, K., Wittchen, H.-U., 2000b. The Early Developmental Stages of Psychopathology Study (EDSP): a methodological update. Eur. Addict. Res. 6, 170182.

- *Lindal, E., Stefansson, J.G., 1993. The lifetime prevalence of anxiety disorders in Iceland as estimated by the US National Institute of Mental Health. Diagnostic Interview Schedule. Acta Psychiatr. Scand. 88 (1), 29-34.

- *Lindeman, S., Hamalainen, J., Isometsa, E., Kaprio, J., Poikolainen, K., Heikkinen, M., Aro, H., 2000. The 12 month prevalence and risk factors for major depressive episode in Finland: representative sample of 5993 adults. Acta Psychiatr. Scand. 102, 178-184.

- Maercker, A., Forstmeier, S., Wagner, B., Glaesmer, H., Brahler, E., 2008a. Post-traumatic stress disorder in Germany. Results of a nationwide epidemiological study. Nervenarzt 79, 577-586.

- $\quad$ Maercker, A., Forstmeier, S., Enzler, A., Krusi, G., Horler, E., Maier, C., et al., 2008b. Adjustment disorders, posttraumatic stress disorder, and depressive disorders in old age: findings from a community survey. Compr. Psychiatry 49, 113-120.

- Maulick, P.K., Mascarenhas, M.N., Mathers, C.D., Dua, T., Saxena, S., 2011. Prevalence of intellectual disability: a meta-analysis of population-based studies. Res. Dev. Disabil. 32, 419436.

- $\quad *$ McConnell, P., Bebbington, P., McClelland, R., Gillespie, K., Houghton, S., 2002. Prevalence of psychiatric disorder and the need for psychiatric care in Nothern Ireland. Population study in the District of Derry. Br. J. Psychiatry 181, 214-219.

- McManus, S., Meltzer, H., Wesseley, S., 2009a. Posttraumatic stress disorder. In: McManus, S., et al. (Ed.), Adult Psychiatric Morbidity in England 2007. NHS: The Health \& Social Care Information Centre. 
- $\quad$ McManus, S., Meltzer, H., Brugha, T., Bebbington, P., Jenkins, R. (Eds.), 2009b. Adult Psychiatric Morbidity in England, 2007: Results of a Household Survey. The Health \& Social Care Information Centre, Social Care Statistics.

- *Meyer, C., Rumpf, H.-J., Hapke, U., John, U., 2001. Prevalence of DSM-IV psychiatric disorders including nicotine dependence in the general population: results from the northern German TACOS study. Neurol. Psychiatr. Br. 9, 75-80.

- Moffitt, T.E., Caspi, A., Taylor, A., et al., 2010. How common are common mental disorders? Evidence that lifetime prevalence rates are doubled by prospective versus retrospective ascertainment. Psychol. Med. 40 (6), 899-909.

- Murray, C.J., Lopez, A.D., 1996. Evidence-based health policy - lessons from the Global Burden of Disease Study. Science 274, 740-743.

- NHS, 2009. The NHS Information Centre, Lifestyles Statistics: Statistics on Alcohol: Online: http://www.ic.nhs.uk/webfiles/publications/alcoholeng2009/Final\%20Format\%20draft\%2020 $09 \% 20 \mathrm{v} 7$.

- $\quad$ Nugent, A.M., Gleadhill, I., McCrum, E., Patterson, C.C., Evans, A., MacMahon, J., 2001. Sleep complaints and risk factors for excessive daytime sleepiness in adult males in Northern Ireland. J. Sleep Res. 10 (1), 69-74 Mar.

- Ohayon, M.M., Bader, G., 2010. Prevalence and correlates of insomnia in the Swedish population aged 19-75 years. Sleep Med. 11 (10), 980-986 Dec.

- Ohayon, M.M., Sagales, T., 2010. Prevalence of insomnia and sleep characteristics in the general population of Spain. Sleep Med. 11 (10), 1010-1018 Dec.

- Ohayon, M.M., Smirne, S., 2002. Prevalence and consequences of insomnia disorders in the general population of Italy. Sleep Med. 3 (2), 115-120 Mar.

- Ohayon, M.M., Guilleminault, C., Priest, R.G., Caulet, M., 1997. Snoring and breathing pauses during sleep: telephone interview survey of a United Kingdom population sample. BMJ 314 (7084),860-863 Mar 22.

- Ohayon, M.M., Priest, R.G., Zulley, J., Smirne, S., Paiva, T., 2002. Prevalence of narcolepsy symptomatology and diagnosis in the European general population. Neurology 58 (12), 1826 1833 Jun 25.

- Olesen, J., Leonardi, M., 2003. The burden of brain diseases in Europe. Eur. J. Neurol. 10, 471-477.

- *Olsen, J., 2004. Prevalence of major depression and stress indicators in the Danish general population. Acta Psychiatr. Scand. 109, 96-103.

- Ott, A., Breteler, M.M., van Harskamp, F., et al., 1995. Prevalence of Alzheimer's disease and vascular dementia: association with education. The Rotterdam study. BMJ 15, 970-973.

- Pakriev, S., Vasar, V., Aluoja, A., Saarma, M., Shlik, J., 1998. Prevalence of mood disorders in the rural population of Udmurtia. Acta Psychiatr. Scand. 97, 169-174.

- Pallesen, S., Nordhus, I.H., Nielsen, G.H., Havik, O.E., Kvale, G., Johnsen, B.H., et al., 2001. Prevalence of insomnia in the adult Norwegian population. Sleep 24 (7), 771-779 Mar.

- Perälä, J., Suvisaari, J., Saarni, S., et al., 2007. Lifetime Prevalence of Psychotic and Bipolar I Disorders in a General Population. Arch. Gen. Psychiatry 64, 19-28.

- Philip, P., Sagaspe, P., Lagarde, E., Leger, D., Ohayon, M.M., Bioulac, B., et al., 2010. Sleep disorders and accidental risk in a large group of regular registered highway drivers. Sleep Med. 11 (10), 973-979 Dec.

- *Pirkola, S., Isometsä, E., Suvisaari, J., Aro, H., Joukamaa, M., Poikolainen, K., Koskinen, S., Aromaa, A., Lönnqvist, J., 2005. DSM-IV mood-, anxiety and alcohol use disorders and their comorbidity in the Finnish general population. Results from the Health 2000 Study. Soc. Psych. Psych. Epid. 40, 1-10.

- Plywaczewski, R., Bednarek, M., Jonczak, L., Zielinski, J., 2008. Sleep-disordered breathing in a middle-aged and older Polish urban population. J. Sleep Res. 17 (1), 73-81 Mar.

- Preisig, M., Waeber, G., Vollenweider, P., et al., 2009. The PsyCoLaus study: methodology and characteristics of the sample of a population-based survey on psychiatric disorders and their association with genetic and cardiovascular risk factors. BMC Psychiatry 9:9 doi:10.1186/1471-244X-9-9. 
- Preti, A., Girolamo, G., et al., 2009. The epidemiology of eating disorders in six European countries: results of the ESEMeD-WMH project. J. Psychiatr. Res. 43 (14), 1125-1132.

- $\quad$ Priebe, S., Bogic, M., Ajdukovic, D., Franciskovic, T., Galeazzi, G.M., et al., 2010. Mental disorders following war in the Balkans. Arch. Gen. Psychiatry 67, 518-528.

- Prince, M., Patel, V., Saxena, S., 2007. No health without mental health. Lancet 9590, 859877.

- Puura, K., Almqvist, F., Tamminen, T., Piha, J., Rasanen, E., Kumpulainen, K., Koivisto, A.M., 1998. Psychiatric disturbances among prepubertal children in southern Finland. Soc. Psychiatry Psychiatr. Epidemiol. 33, 310-318.

- Rahkonen, 2003. Dementia with Lewy bodies according to the consensus criteria in general population aged 75 years or older. J. Neurol. Neurosurg. Psychiatry 74, 720-724.

- Rehm, J., Room, R., van den Brink, W., Jacobi, F., 2005a. Alcohol use disorders in EU countries and Norway: an overview of the epidemiology. Eur. Neuropsychopharmacol. 15 (4), 377-388.

- Rehm, J., Room, R., van den Brink, W., Kraus, L., 2005b. Problematic drug use and drug use disorders in EU countries and Norway: an overview of the epidemiology. Eur. Neuropsychopharmacol. 15 (4), 389-397.

- Riedel-Heller, G., 2001. Prevalence of dementia according to DSMIII-R and ICD-10. Results of the Leipzig Longitudinal Study of the Aged (LEILA $75+$ ). Part 1. Br. J. Psychiatry 179, 250-254.

- Riedel-Heller, S., Busse, A., Angermeyer, C., 2006. The state of mental health in old-age across the "old" European Union - a systematic review. Acta Psychiatrica Scandinavia 113, 388-401.

- $\quad$ Rice, D.P., Miller, L.S., 1998. Health economics and cost implications of anxiety and other mental disorders in the United States. Br. J. Psychiatr. 173 (Suppl. 34), 4-9.

- $\quad$ *Rihmer, Z., Szadoczky, E., Furedi, J., Kiss, K., Papp, Z., 2001. Anxiety disorders comorbidty in bipolar I, bipolar II and unipolar major depression: results from a population-based study in Hungary. J. Affect. Disord. 67, 175-179.

- $\quad$ Robins, L.N., Helzer, J.E., Croughan, J., Ratcliff, K.S., 1981. National Institute of Mental Health Diagnostic Interview Schedule: its history, characteristics and validity. Arch. Gen. Psychiatry 38, 381-389.

- $\quad$ Robins, L.N., Wing, J., Wittchen, H.-U., Helzer, J.E., Babor, T.F., Burke, J., Farmer, A., Jablenski, A., Pickens, R., Regier, D.A., Sartorius, N., Towle, L.H., 1988. The Composite International Diagnostic Interview: an epidemiological instrument suitable for use in conjunction with different diagnostic systems and in different cultures. Arch. Gen. Psychiatry $45,1069-1077$.

- Rothman, K.J., Greenland, S., Lash, T.L., 2008. Modern Epidemiology, 3 rd ed. Lippincott, Williams \& Wilkins, Philadelphia, USA.

- Salvador-Carulla, L., Bertelli, M., 2008. 'Mental retardation' or 'intellectual disability': time for a conceptual change. Psychopathology 41, 10-16 (+ original data from POMONA study).

- Salvador-Carulla, L., Reed, G.M., Vaez-Azizi, L.M., Cooper, S.A., Martinez-Leal, R., Bertelli, M., Adnams, C., Cooray, S., Deb, S., Akuory-Dirani, L., Girimaji, S.C., Katz, G., Kwok, H., Luckasson, R., Simeonsson, R., Walsh, C., Munir, K., Saxena, S., in press.

- Intellectual developmental disorders: towards a new name, definition and framework for "mental retardation/intellectual disability" in ICD-11. World Psychiatry, 10 (3).

- Saxena, S., Thornicroft, G., Knapp, M., Whiteford, H., 2007. Global Mental Health 2 resources for mental health: scarcity, inequity, and inefficency. Lancet 370, 878-889.

- *Singleton, N., Bumpstead, R., O'Brien, M., Lee, A., Meltzer, H., 2001. Psychiatric morbidity among adults living in private households. National Statistics, 154. The Stationery Office, London.

- Schalock, R.L., Luckasson, R.A., Shorgren, K.A., 2007. The Remaining of Mental Retardation: Understanding the Change to the Term Intellectual Disability. Intellect. Dev. Disabil. 45 (2), 116-124.

- $\quad$ Spijker, J., de Graaf, R., Bijl, R.V., Beekman, A.T.F., Ormel, J., Nolen, W.A., 2004. Functional disability and depression in the general population. Results from the Netherlands 
Mental Health Survey and Incidence Study (NEMESIS). Acta Psychiatr. Scand. 110, 208214.

- Stefánsson, J.-G., Líndal, E., 2009. The prevalence of mental disorders in the GreaterReykjavik area. Laeknabladid 95, 559-564.

- *Stefánsson, J.-G., Líndal, E., Björnsson, J.-K., Guômundsdóttir, Á., 1991. Lifetime prevalence of specific mental disorders among people born in Iceland in 1931. Acta Psychiatr. Scand. 84,142-149.

- Steinhausen, H.-C., Winkler, M.C., Meier, M., Kannenberg, R., 1998. Prevalence of child and adolescent psychiatric disorders: the Zürich Epidemiological Study. Acta Psychiatr. Scand. 98,262-271.

- Stouthard, M.E.A., Essink-Bot, M.L., Bonsel, G.J., Barendregt, J.J., Kramer, P.G., van de Water, H.P.A., Gunning-Schepers, L.J., van der Maas, P.J., 1997. Disability Weights for Diseases in the Netherlands. Erasmus University, Rotterdam.

- Stradling, J.R., Crosby, J.H., 1991. Predictors and prevalence of obstructive sleep apnoea and snoring in 1001 middle aged men. Thorax 46 (2), 85-90 Feb.

- Stradling, J.R., Barbour, C., Glennon, J., Langford, B.A., Crosby, J.H., 2000. Prevalence of sleepiness and its relation to autonomic evidence of arousals and increased inspiratory effort in a community based population of men and women. J. Sleep Res. 9 (4), 381-388 Dec.

- *Szadoczky, E., Papp, Z., Vitrai, J., Rihmer, Z., Furedi, J., 1998. The prevalence of major depressive and bipolar disorders in Hungary. J. Affect. Disord. 50, 153-162.

- *Szadoczky, E., Rihmer, Z., Papp, Z., Vitrai, J., Füredi, J., 2002. Gender differences in major depressive disorders in a Hungarian community survey. Int. J. Psychiatry. Clin. 6, 31-37.

- Taylor, E., Sandberg, S., 1991. The Epidemiology of Childhood Hyperactivity. Oxford University Press, Oxford.

- $\quad$ Teculescu, D., Mayeux, L., Montaut-Verient, B., Michaely, J.P., Mur, J.M., 1998. An epidemiologic study of sleep-disordered breathing in the male population of Lorraine: preliminary results. Sante Publique 10 (2), 177-190 Jun.

- ten Have, M., de Graaf, R., Vollebergh, W., Beekman, A., 2004. What depressive symptoms are associated with the use of care services? Results from the Netherlands Mental Health Survey and Incidence Study (NEMESIS). J. Affect. Disord. 80, 239-248.

- Tognoni, G., Ceravolo, R., Nucciarone, B., et al., 2005. From mild cognitive impairment to dementia: a prevalence study in a district of Tuscany. Acta Neurol. Scand. 112 (2), 65-71 (Aug).

- Torgersen, S., Kringlen, E., Cramer, V., 2001. The prevalence of personality disorders in a community sample. Arch. Gen. Psychiatry 58, 590-596.

- Torres, A.R., Prince, M.J., et al., 2006. Obsessive-compulsive disorder: prevalence, comorbidity, impact, and help-seeking in the British National Psychiatric Morbidity Survey of 2000. Am. J. Psychiatry 163 (11), 1978-1985.

- Tsolaki, M., Fountoulakis, C., Pavlopoulos, I., et al., 1999. Prevalence and incidence of Alzheimer disease and other dementing disorders in Pylea, Greece. Am. J. Alzheimers Dis. Other Demen. 14, 138.

- *Tylee, A., Gastpar, M., Lepine, J.P., 1999. Identification of depressed patient types in the community and their treatment needs: findings from the DEPRES II (Depression Research in European Society II). Survey. Int. Clin. Psychopharmacol. 14, 153-165.

- Verhulst, F.C., van der Ende, J., Kasius, M.C., 1997. The prevalence of DSMIII-R diagnoses in a national sample of Dutch adolescents. Arch. Gen. Psychiatry 54, 326-329.

- Vicente, J., Klempova, D., Matias, J., Olszewski D., Simon, R., 2010. Prevalence of intensive forms of cannabis use in the European Union and Norway. Unpublished manuscript.

- von Strauss, E., Viitanen, M., De Ronchi, D., et al., 1999. Aging and the occurrence of dementia: findings from a population-based cohort with a large sample of nonagenarians. Arch. Neurol. 56 (5),587-592.

- *Wacker, H.-R., 1995. Anxiety and Depression. An Epidemiological Investigation. Huber, Bern.

- WHO Euro., 2010. European Status Report on Alcohol and Health 2010. WHO Euro, Copenhagen. 
- Wing, J.K., Barbor, T., Brugha, T., Cooper, J.E., Giel, R., Jablenski, A., Regier, D., Sartorius, N., 1990. SCAN: Schedules for Clinical Assessment in Neuropsychiatry. Arch. Gen. Psychiatry 47,589-593.

- Wittchen, H.-U., 2000. Met and unmet need for interventions in community cases with anxiety disorders. In: Andrews, G., Henderson, S. (Eds.), Unmet Need in Psychiatry. Problems, Resources, Responses. Cambridge University Press, Cambridge, pp. 256-276.

- Wittchen, H.-U., 2002. Generalized anxiety disorder: prevalence, burden and cost to society. Depress. Anxiety 16, 162-171.

- Wittchen, H.-U., Jacobi, F., 2005. Size and burden of mental disorders in Europe - a critical review and appraisal of 27 studies. Eur. Neuropsychopharmacol. 15 (4), 357-376.

- *Wittchen, H.-U., Essau, C.-A., von Zerssen, D., Krieg, J.-C., Zaudig, M., 1992. Lifetime and six-month prevalence of mental disorders in the Munich Follow-Up Study. Eur. Arch. Psychiatry Clin. Neurosci. 241, 247-258.

- $\quad$ *Wittchen, H.-U., Nelson, C.B., Lachner, G., 1998. Prevalence of mental disorders and psychosocial impairments in adolescents and young adults. Psychol. Med. 28, 109-126.

- Wittchen, H.U., Krause, P., Höfler, M., Pittrow, D., Winter, S., Spiegel, B., et al., 2001. NISAS-2000: the "Nationwide Insomnia Screening and Awareness Study". Prevalence and interventions in primary care. Fortschr. Med. Orig. 119 (1), 9-19.

- Wittchen, H.-U., Jönsson, B., Olesen, J., 2005. Editorial: towards a better understanding of the size and burden and cost of brain disorders in Europe. Eur. Neuropsychopharmacol. 15 (4),355-356.

- World Health Organisation, 2001. The World Health Report 2001 - Mental Health: New Understanding, New Hope. WHO, Geneva.

- World Health Organisation, 2002. World Health Report 2002. Reducing Risks, Promoting Healthy Life. WHO, Geneva.

- World Health Organisation, 2005. WHO Mental Health Atlas 2005 (Revised Edition). Mental Health: Evidence and Research. Department of Mental Health and Substance AbuseWHO, Geneva.

- World Health Organisation, 2008. The Global Burden of Disease: 2004 Update. WHO, Geneva, Switzerland.

- World Health Organization, 1993. Tenth revision of the international classification of diseases, Chapter V (F): mental and behavioural disorders. Clinical Descriptions and Diagnostic Guidelines. World Health Organization, Geneva.

- Zatonski, W., Manczuk, M., Sulkowska, U., HEM Project Team, 2008. Closing the health gap in the European Union. Cancer Epidemiology and Prevention Division, the Maria Sklodowska-Curie Memorial Cencer Center and Institute of Oncology, Warsaw, Poland. 